\title{
DIREITOS DAS CRIANÇAS, POLÍTICAS DE DESENVOLVIMENTO E PRÁTICAS EMPRESARIAIS: PARÂMETROS DE GARANTIAS JURÍDICAS NOS GRANDES EMPREENDIMENTOS NO BRASIL
}

\author{
CHILDREN'S RIGHTS, DEVELOPMENT POLICIES AND BUSINESS: \\ PARAMETERS OF LEGAL GUARANTEES IN THE LARGE \\ ENTREPRENEURSHIPS IN BRAZIL
}

Assis da Costa Oliveira

André Filipe Pereira Reid dos Santos

\section{Resumo}

0 presente artigo objetiva analisar as proposições de garantias jurídicas às crianças e aos adolescentes no contexto das políticas de desenvolvimento e das práticas empresariais relacionadas aos grandes empreendimentos econômicos no Brasil. Por meio de pesquisa documental, discutem-se quatro linhas de proposições: fortalecimento da rede de proteção dos territórios afetados por grandes empreendimentos; mudança do licenciamento ambiental para internalização de garantias jurídicas às crianças e aos adolescentes; definição de parâmetros de responsabilização jurídica das empresas que gerenciam tais empreendimentos; democratização da participação social e do protagonismo de crianças e adolescentes nos espaços de decisão dos empreendimentos. Da análise das proposições, conclui-se que constituem fontes de expansão das fronteiras dos direitos humanos e recursos interpretativos para adequação das políticas e das práticas empresariais via força hermenêutico-normativa dos direitos das crianças e dos adolescentes.

Palavras-Chave: direitos das crianças e adolescentes; políticas de desenvolvimento; práticas empresariais.

\section{Abstract}

This article aims to analyze the proposals of legal guarantees to children and adolescents in the context of development policies and business prac- 
tices related to the large entrepreneurships in Brazil. Through documentary research, we discuss four lines of proposals: strengthening the protection network of the affected territories by large entrepreneurships; changing environmental licensing for internalization of legal safeguards for children and adolescents; definition of parameters of legal responsibility of the businesses that manage such projects; democratization of social participation and protagonism of children and adolescents in decision-making spaces of the projects. From the analysis of the propositions, concluded that constitute sources of expansion of the borders of human rights and interpretative resources for the adequacy of development policies and business through hermeneutic and normative force of the rights of children and adolescents.

Keywords: children and adolescents rights; development policies; business practices.

\section{INTRODUÇÃo}

Em 1989, realizou-se na cidade de Belém, estado do Pará, o Seminário "As Crianças da Amazônia", com o objetivo de estabelecer uma linha de reflexão sobre a situação da infância no contexto amazônico latino-americano. Ao longo dos dias de debate foram definidas conclusões e recomendações que iniciam a tematização de propostas fazendo um balanço histórico das condições de vida das crianças, eclipsando como problemática central, no relatório final do evento, o fato de que "[a] situação dramática enfrentada pelas crianças na Amazônia não pode ser analisada senão como resultante de um drama econômico" (FRANCO, LEAL, 1990, p. 413), cujo núcleo estava na identificação da expansão do capital internacional sobre o território amazônico e os consequentes impactos negativos de pobreza e desigualdades sociais.

Naquele momento, destacava-se a centralidade da atenção nas ações estatais de investimento em políticas de desenvolvimento e as afetações às condições de vida das crianças e adolescentes, descortinando um campo de investigação acadêmica e de atuação militante que mesclava a problematização das escolhas político-ideológicas de planejamento e investimento econômico com o tensionamento das responsabilidades estatais para efetivação das garantias jurídicas e para transformação do modelo de desenvolvimento vigente. 
Nesse campo, o desafio está na incidência do denominado "enfoque dos direitos humanos"1 nas políticas de desenvolvimento - assim como no conjunto mais amplo das políticas públicas - que consiste na compreensão dos tratados internacionais de direitos humanos e dos direitos fundamentais estabelecidos nas constituições nacionais como marcos conceituais capazes de oferecer um sistema coerente de princípios e regras para adequação da lógica do desenvolvimento (ABRAMOVICH, 2004; JIMÉNEZ BENÍTEZ, 2007; VÁZQUEZ, DELAPLACE, 2011), operacionalizando, fundamentalmente, a indivisibilidade dos direitos humanos como pressuposto ético e instrumental às políticas de desenvolvimento.

Porém, com o avanço da privatização dos serviços públicos ao longo da década de 1990, deslocando a oferta de direitos sociais básicos à iniciativa privada, e a incapacidade dos Estados de regular os impactos negativos das empresas transnacionais na nova égide da globalização econômica, colocou-se em evidencia a necessidade de definição de parâmetros internacionais de responsabilização jurídicas das empresas para respeitar os direitos humanos (GERBER, KYRIAKAKIS, O'BYRNE, 2013; MARTIN-ORTEGA, WALLACE, 2013). Em 2011, com a elaboração dos Princípios Operativos Empresas e Direitos Humanos (POEDH) da Organização das Nações Unidas (ONU), a discussão tomou um salto de aprofundamento da capacidade de responsabilização jurídica das empresas para identificar, prevenir, mitigar e reparar as violações de direitos humanos que ocorram devido as suas atividades, ou relacionadas à cadeia produtiva e aos clientes.

Tais questões não interessam apenas ao Brasil, país alvo do presente estudo, mas representam um cenário latino-americano atual que difere daquele existente no ano de 1989, pois se vive hoje os influxos de um processo neodesenvolvimentista ${ }^{2}$ de articulação econômica regional inaugurada com a Integração das Infraestruturas Regionais Sul-Americanas (IIRSA), no ano 2000, cujo internalização nos Estados nacionais ocorreu por diferentes estratégias macroeconômicas, sendo a vertente brasileira o Programa Avança Brasil (1998-2002) e o atual Programa de Aceleração do Crescimento (PAC), em suas versões um (2007-2010) e dois (2011 em diante).

Ao longo da primeira década do século XX, o avanço dos investimentos estatais em empreendimentos de infraestrutura de grande escala 
(hidrelétricas, portos, rodovias, hidrovias, etc.), articulado à expansão da exploração dos recursos naturais (energia, soja, minério, gás, etc.) por empresas nacionais ou transnacionais, colocou em evidencia às instituições do Sistema de Garantia de Direitos ${ }^{3}$ (SGD) no Brasil, em particular o Conselho Nacional dos Direitos da Criança e do Adolescente (CONANDA) e o Comitê Nacional de Enfrentamento da Violência Sexual Contra Crianças e Adolescentes (CNEVSCA), a necessidade de ampliar o debate sobre as violações de direitos às crianças e aos adolescentes que ocorrem em cenários de implantação de grandes empreendimentos.

Com isso, as mobilizações socioestatais realizadas com o advento do novo século tinham por marco de conteúdo inicial as consequências negativas aos direitos sexuais de crianças e adolescentes - certamente devido à influência do III Congresso Mundial de Enfrentamento da Violência Sexual Contra Crianças e Adolescentes ${ }^{4}$, realizado no Rio de Janeiro, em 2008 - e por enfoque geográfico as maiores obras do PAC em andamento no território nacional: as Usinas Hidrelétricas de Belo Monte, na cidade de Altamira, estado do Pará; e as Usinas Hidrelétricas de Jirau e Santo Antônio, na cidade de Porto Velho, estado de Rondônia 5 .

Assim, entre 2011 e 2013 diversas instituições públicas e entidades sociais, organizadas numa Rede de Enfrentamento da Violência Sexual Contra Crianças e Adolescentes (REVSCA) - composta por uma quantidade considerável de organizações, especialistas e militantes dos direitos das crianças e dos adolescentes, e que passou a se articular em seminários e audiências públicas realizados nas duas regiões de implantação das maiores obras de hidrelétrica PAC -, produziu cinco documentos políticos denominados de "Carta de Porto Velho" (CNEVSCA, 2011), "Exploração Sexual e Grandes Obras” (CHILDHOOD, 2011), "Carta 18 de Maio” (CNEVSCA, 2012), "Pacto do Conselho Nacional dos Direitos da Criança e do Adolescente" (CONANDA, 2012), e a "Carta de Altamira” (CNEVSCA, 2013), que trazem uma variedade de proposições visando à modificação substancial das condições atuais de tratamento às crianças e aos adolescentes nas regiões afetadas por grandes empreendimentos, especialmente na Amazônia, ante a vigência do paradigma constitucional da proteção integral ${ }^{6}$.

A mobilização nacional empreendida deu visibilidade e agenda política às implicações que as políticas de desenvolvimento e as prá- 
ticas empresariais têm para a precarização das condições de vida das crianças e dos adolescentes no contexto dos grandes empreendimentos, mas, fundamentalmente, trabalharam a violência sexual como pólo de convergência de um conjunto de outras violações e vulnerabilidades cuja intervenção demandava a adoção de uma abordagem integral ou interdependente dos direitos das crianças e dos adolescentes, incidindo-os nas normativas, políticas, procedimentos, instrumentais e agentes ligados ao planejamento territorial, à política ambientalista e aos negócios.

Portanto, com base na pesquisa documental, objetiva-se realizar a análise do conteúdo dos documentos produzidos pela REVSCA, tendo em vista a organização do conteúdo em quatro eixos estruturais (convertidos, também, nos quatro tópicos do trabalho): fortalecimento da rede de proteção nos territórios afetados por grandes empreendimentos; adequação do licenciamento ambiental via incidência dos direitos das crianças e dos adolescentes; responsabilização jurídica das empresas para respeito aos direitos humanos; e, participação social e protagonismo infanto-adolescente nos espaços de decisão dos grandes empreendimentos.

\section{FORTALECIMENTO DA REDE DE PROTEÇÃO}

Territórios de implantação de grandes empreendimentos são alvos de processo de intensificação da migração e da circulação de recursos econômicos que promovem diferentes formas de afetação negativa à população e ao meio ambiente, gerando, também, novas demandas de atendimento pelos serviços públicos que, em geral, ocasiona a sobrecarga ou o esgotamento da capacidade estatal, haja vista a inexistência ou deficiência de planejamento das políticas públicas para suportar as dinâmicas demográficas. Com isso, tem-se um cenário de reprodução histórica da precarização das condições de vida que promove o acirramento dos riscos de violações de direitos de crianças e adolescentes, algo bem delineado na "Carta 18 de maio":

Destacamos a ocorrência de grandes fluxos migratórios não planejados, rápida urbanização irregular e precária, vulnerabilização de assentamentos já consolidados, destruição de cadeias produtivas tradicionais. Estes 
processos concorrem para o aumento dos casos de homicídios, estupro, exploração sexual, trabalho infantil, subnotificação do registro de nascimento, paternidade não reconhecida e irresponsável, gravidez não planejada, doenças sexualmente transmissíveis, drogadição, precarização do trabalho, ampliação de transtornos mentais (CNEVSCA, 2011, p. 1).

Para fazer frente aos cenários históricos e atuais, a REVSCA elaborou uma série de proposições para incidência no planejamento territorial das políticas públicas direcionadas às crianças e aos adolescentes, tendo em vista o caráter temporal dos grandes empreendimentos e a condição peculiar de pessoas em desenvolvimento, cujo quadro abaixo (Quadro 1) sistematiza as propostas.

\section{Quadro 1. Sistematização das proposições}

\begin{tabular}{|c|l|}
\hline Documentos & \multicolumn{1}{c|}{ Conteúdo } \\
\hline $\begin{array}{c}\text { Carta de Porto } \\
\text { Velho } \\
\text { (CNEVSCA, 2011) }\end{array}$ & $\begin{array}{l}\text { "Ampliar a rede de serviços públicos com a antecedência neces- } \\
\text { sária para atender o aumento populacional previsto" (p. 4). } \\
\text { rantia dos Direitos da Criança e do Adolescente" (Idem). } \\
\text { "Garantir, em longo prazo, que as riquezas geradas pelos empre- } \\
\text { endimentos possam ser revertidas em favor das comunidades, } \\
\text { respeitando a cultura local, por meio da implantação e imple- } \\
\text { mentação de políticas públicas e de fundos de reparaça" (Idem). }\end{array}$ \\
$\begin{array}{c}\text { Exploração } \\
\text { Obras }\end{array}$ & $\begin{array}{l}\text { "Qualificar a administração pública municipal para atuar so- } \\
\text { bre problemas decorrentes da implantação de grandes em- } \\
\text { preendimentos que incidem principalmente sobre o território } \\
\text { municipal. Nesse âmbito, deve caber aos empreendedores/ } \\
\text { (CHILDHOOD, } \\
\text { construtores, bem como aos governos estaduais e federal, } \\
\text { prestar apoio técnico, operacional, executivo e financeiro para } \\
\text { que o município possa fazer face às demandas que recebe por } \\
\text { força da implantação de grandes empreendimentos em seu } \\
\text { território" (p. 14). } \\
\text { "Planejar todo o andamento das obras, nas fases de instalação, } \\
\text { implantação e operação. Compreende-se a operação até o mo- } \\
\text { mento em que todo o ciclo da obra está finalizado" (Idem). } \\
\text { "Planejar e fazer o diagnóstico social amplo do território, da } \\
\text { região em que a obra vai ser implantada e, portanto, também } \\
\text { de seu entorno" (Idem). } \\
\text { "Fortalecer as políticas públicas em geral, assistência social, } \\
\text { saúde, educação etc., a fim de preparar com antecedência o } \\
\text { território para o momento em que a obra tenha o pico de rece- } \\
\text { bimento de trabalhadores" (Idem). }\end{array}$ \\
\hline
\end{tabular}




\begin{tabular}{|c|c|}
\hline $\begin{array}{l}\text { Exploração } \\
\text { Sexual e Grandes } \\
\text { Obras } \\
\text { (CHILDHOOD, } \\
\text { 2011) }\end{array}$ & $\begin{array}{l}\text { "Fortalecer e empoderar instâncias fiscalizadoras, compreen- } \\
\text { dendo as Câmaras Municipais, conselhos e instituições congê- } \\
\text { neres (p. 15). } \\
\text { "Negociar com os governos locais a implantação de conselhos } \\
\text { tutelares, para atender ao aumento de demanda que ocorre ao } \\
\text { longo de todo o ciclo de obras" (Idem). } \\
\text { "Assegurar que os serviços públicos cheguem qualificadamente, } \\
\text { de modo efetivo e eficaz no território municipal" (Idem). } \\
\text { "Elaborar ou atualizar o plano municipal de enfrentamento da } \\
\text { violência sexual contra crianças e adolescentes" (p. 16). } \\
\text { "Fortalecer os conselhos (de direitos e tutelares) e o sistema } \\
\text { de garantia dos direitos" (Idem). } \\
\text { "Fortalecer a rede de produção local, com vistas a absorver } \\
\text { seus serviços e produtos na estrutura da obra" (p. 17). } \\
\text { "Fiscalizar as condições de trabalho mais efetiva pelo Minis- } \\
\text { tério do Trabalho e demais órgãos fiscalizadores" (Idem). } \\
\text { "Garantia de espaços de entretenimento de qualidade - criar } \\
\text { áreas de lazer e ações relacionadas à educação, cultura, espor- } \\
\text { tes etc. (p. 18). }\end{array}$ \\
\hline $\begin{array}{l}\text { Carta } 18 \text { de maio } \\
\text { (CNEVSCA, 2012) }\end{array}$ & $\begin{array}{l}\text { "Consideramos relevante que as casas parlamentares criem } \\
\text { painéis ou comissões especiais independentes plurais, com a } \\
\text { da sociedade civil brasileira, para monitoramento dos grandes } \\
\text { empreendimentos de infraestrutura e referentes aos Megae- } \\
\text { ventos" (p. 3). }\end{array}$ \\
\hline $\begin{array}{c}\text { Pacto CONANDA } \\
\text { (CONANDA, 2012) }\end{array}$ & $\begin{array}{l}\text { "Destinar recursos direcionados para Amazônia de forma dife- } \\
\text { renciada, visando atender as especificidades regionais e locais, } \\
\text { territórios de povos e comunidades tradicionais, em especial } \\
\text { de áreas ribeirinhas, indígenas e quilombolas, sobretudo nas } \\
\text { regiões dos grandes projetos" (p. 1). } \\
\text { "Fortalecer a política de Proteção social do SUAS [Sistema Úni- } \\
\text { co da Assistência Social] com ampliação dos equipamentos, } \\
\text { serviços e programas de media e alta complexidade, tipifica- } \\
\text { das pelo CNAS" (Idem). } \\
\text { "Investir recursos do fundo da criança e do adolescente para } \\
\text { formação/capacitação continuada e permanente de conselhei- } \\
\text { ros de direitos e setoriais na função institucional de controle so- } \\
\text { cial, especialmente no monitoramento das ações do plano com } \\
\text { base no diagnóstico das ações proposta e já executadas" (Idem). } \\
\text { "Construir escolas com salas de aulas adequadas para no máxi- } \\
\text { mo } 30 \text { alunos, quadras de esportes cobertas" (Idem). } \\
\text { "Criar e revitalizar espaços de convivência, cultura e lazer e } \\
\text { esportes" (p. 2). }\end{array}$ \\
\hline
\end{tabular}




\begin{tabular}{|c|c|}
\hline $\begin{array}{c}\text { Pacto CONANDA } \\
\text { (CONANDA, 2012) }\end{array}$ & $\begin{array}{l}\text { "Construir uma unidade de medida socioeducativa de interna- } \\
\text { ção a partir do plano estadual de atendimento socioeducativo, } \\
\text { em consonância com o plano estadual e municipal de atendi- } \\
\text { mento socioeducativo" (p. 3). } \\
\text { "Fortalecer a atuação dos membros do Tribunal de Justiça, Mi- } \\
\text { nistério Público e Defensoria Pública junto aos Conselhos de } \\
\text { Direitos, Conselhos Tutelares e demais conselhos estratégicos } \\
\text { para a garantia de direitos da criança e do adolescente" (Idem). } \\
\text { "Implementar os conselhos tutelares a partir da deliberação } \\
\text { dos CMDCAS e em conformidade com a resolução } 139 \text { do Co- } \\
\text { nanda e lei municipal" (Idem). } \\
\text { "Mobilizar os atores do SGD para a elaboração da Política } \\
\text { Regional da Infância e da Adolescência e o Plano Decenal } \\
\text { da região do Xingu, com financiamento das três esferas de } \\
\text { governo" (Idem). }\end{array}$ \\
\hline $\begin{array}{c}\text { Carta de } \\
\text { Altamira } \\
(\mathrm{CNEVSCA}, 2013)\end{array}$ & $\begin{array}{l}\text { "Política de fixação e valorização dos profissionais que atuam nas } \\
\text { instituições que atuam diretamente nos locais onde são implanta- } \\
\text { dos grandes obras de infraestrutura e de apropriação de recursos } \\
\text { naturais, devido o aumento do custo de vida social que acarreta a } \\
\text { dificuldade de permanência destes profissionais" (p. 4). } \\
\text { "Formação continuada dos atores da Rede de Atendimento, } \\
\text { Segurança Pública, Conselho Tutelar e Conselho Municipal dos } \\
\text { Direitos da Criança e do Adolescente sobre ações que podem } \\
\text { ser realizadas no enfrentamento à violência sexual de crian- } \\
\text { ças, adolescentes e mulheres no cenário das grandes obras, em } \\
\text { especial do tráfico de pessoas para fins de exploração sexual e } \\
\text { do tráfico de drogas" (Idem). } \\
\text { "Implantação de mais Conselhos Tutelares, e estruturação dos } \\
\text { existentes, e fortalecimento do Fundo Municipal dos Direitos } \\
\text { da Criança e do Adolescente nos locais de implantação de } \\
\text { grandes obras de infraestrutura e de apropriação dos recursos } \\
\text { naturais" (p. 5). } \\
\text { "Criação ou fortalecimento, em todos os locais impactados por } \\
\text { grandes obras de infraestrutura e apropriação de recursos na- } \\
\text { turais, de Juizados, Promotorias e Defensorias especializadas } \\
\text { nos direitos das crianças e dos adolescentes, e que contenham } \\
\text { equipe multidisciplinar" (p. 6). }\end{array}$ \\
\hline
\end{tabular}

Fortalecimento prévio e continuado da rede de serviços públicos de atendimento às crianças e aos adolescentes é o núcleo das proposições apresentadas no quadro acima e é também a tradução do direito ao desenvolvimento na perspectiva dos direitos humanos, ou seja, metas de melhoria da qualidade de vida que passam a ser cobradas na condição de direitos ${ }^{7}$ (JIMÉNEZ BEN, 2007; NWAUCHE, NWOBIKE, 2005) a serem 
prestados para estabelecer o legado do desenvolvimento: a democratização do acesso aos bens e serviços públicos para a superação de desigualdades e violências.

Por fortalecimento quer-se dizer investimento financeiro e político por meio da priorização do planejamento dos territórios alvo da implantação de grandes empreendimentos, mas não como uma moeda de troca ou contrapartida socioeconômica, antes sim pelo reconhecimento do caráter mandamental dos direitos das crianças e dos adolescentes relacionados às condutas e decisões.

Com isso, busca-se fomentar o trabalho desde a lógica da atuação preventiva e preparatória às configurações populacionais a serem posteriormente identificadas no processo de implantação dos grandes empreendimentos. Trata-se de priorização do planejamento territorial que precisa continuar ao longo do ciclo temporal dos empreendimentos e para além deles, é dizer, pensando nas demandas e nos serviços à longo prazo, pois não cabe restringir a garantia de direitos ao ciclo econômico dos empreendimentos, mas sim à condição de sujeitos de direitos de crianças e adolescentes e às prestações obrigacionais que família, sociedade e Estado lhes devem prestar, de maneira ininterrupta, ante a vigência do paradigma da proteção integral.

Certamente, a sustentabilidade da qualidade estrutural e operacional da rede de proteção está fortemente vinculada ao fortalecimento do controle social e da capacidade de monitorar das demandas deflagradas em cada período do ciclo dos grandes empreendimentos. Nisso, o conteúdo reivindicatório da REVSCA evidencia que ao fortalecimento dos investimentos na rede de proteção antepõe-se e justapõe-se o potencial de mobilização e articulação da sociedade civil e dos movimentos sociais para organizarem estratégias políticas de reivindicação de direitos “de baixo para cima”, sendo este, em muitos casos, o principal ganho à conquista de outras melhorias e de cumprimento aos direitos de crianças e adolescentes.

Particular atenção é direcionada à escala municipal da rede de proteção, pois representa pensar na articulação entre os entes federativos para fortalecer o caráter municipal da política de atendimento às crianças e aos adolescentes. Segundo Martins (2009), a municipalização do atendimento, sendo uma das inovações do paradigma da proteção integral 
advindo com a Constituição Federal de 1988 (CF/88) e o Estatuto da Criança e do Adolescente (ECA - Lei no. 8.069/1990), representa a possibilidade de descentralização gerencial das políticas públicas para maior participação social e interação interinstitucional, mas, nos territórios de implantação de grandes empreendimentos, exige maior capacidade de compartilhamento dos custos de investimentos para não sobrecarregar apenas a instância municipal, quase sempre a de menor capacidade de arrecadação de recursos entre as três esferas governamentais.

Por outro lado, há um enfoque específico na formação continuada e na melhoria das condições de trabalho dos profissionais do SGD, objetivando qualificar a atuação nas circunstâncias presentes em contextos de grandes empreendimentos, assim como evitar o êxodo migratório dos profissionais devido o aumento do custo de vida e/ou a transferência destes para as empresas ligadas ao empreendimento (MARIN, OLIVEIRA, 2015; OLIVEIRA, 2013, 2014b).

\section{RECONFIGURAÇÃO DO LICENCIAMENTO AMBIENTAL}

O direito ambiental introduzido no Brasil a partir da década de 1980 do Século XX procurou reorientar os mecanismos jurídicos de proteção e preservação do meio ambiente com base no paradigma do desenvolvimento sustentável e do reconhecimento do direito ao meio ambiente como um direito humano difuso, ou seja, pertencente à humanidade e dever de proteção por parte de todos.

Nesse cenário, a regulamentação jurídica sobre a previsão e intervenção qualificada nos denominados danos socioambientais ${ }^{8}$ produzidos pela implantação de atividades produtivas foi uma das principais questões abordadas, possuindo delimitações legais no inciso IV, artigo 225 da CF/88, artigo 9o da Lei no. 6.938/1991 (Política Nacional de Meio Ambiente), além de detalhamentos regulatórios nas Resoluções nso. 001/1986, 237/1997 e 279/2001 do Conselho Nacional de Meio Ambiente (CONAMA). A maior inovação foi a introdução do procedimento administrativo do licenciamento ambiental com a finalidade de controlar e, por vezes, impedir a condução de atividade econômica cujos danos socioambientais 
não fossem previamente estabelecidos - mediante Estudo de Impacto Ambiental (EIA) e Relatório de Impacto sobre o Meio Ambiente (RIMA) - e adequadamente evitados, mitigados e/ou compensados por meio de medidas condicionantes que "condicionariam" a liberação das licenças prévia, de instalação e de operação do empreendimento.

No entanto, desde as primeiras movimentações da REVSCA, em 2011, a crítica à qualidade da regulamentação jurídica - especialmente quanto à invisibilidade social e restrição da capacidade técnica de identificação dos danos sociais às crianças e aos adolescentes nos estudos prévios e nas condicionantes (OLIVEIRA, 2013, 2014b; OLIVEIRA, CONCEIÇÃO, HORIZONTE, 2014; SCABIN, 2015) - e à "adequação"9 (ZHOURI, 2013) do licenciamento aos interesses político-econômicos particulares ${ }^{10}$ - transmutando-os em interesses de utilidade pública ou de identidade nacional (CASTRO, 2010) - revelam a distribuição desigual de danos e benefícios e a proliferação de "lacunas nas condicionantes"11 (OLIVEIRA, 2015), assim como a "preferência por minimizar a avaliação dos efeitos, antes mesmo de se pensar em minimizar os próprios efeitos" (SIGAUD, 1989, p. 66), sobretudo se implicar em alterações no cronograma das obras civis.

Contra isso, situa-se a crítica fomentadora de novas proposições ao licenciamento ambiental estruturadas na internalização de preceitos dos direitos das crianças e dos adolescentes, conforme se pode analisar no quadro (Quadro 2) a seguir:

\section{Quadro 2. Sistematização das proposições}

\begin{tabular}{|c|l|}
\hline Documentos & \multicolumn{1}{c|}{ Conteúdo } \\
\hline $\begin{array}{c}\text { Carta de Porto } \\
\text { Velho } \\
\text { (CNEVSCA, 2011) }\end{array}$ & $\begin{array}{l}\text { "Inserir, no marco legal para licenciamento e financiamento } \\
\text { destas obras, medidas condicionantes e cláusulas sociais asse- } \\
\text { curatórias dos direitos das comunidades locais, especialmente } \\
\text { de crianças e adolescentes, a serem desenvolvidas no processo } \\
\text { de instalação e operação do empreendimento" (p. 3). } \\
\text { "Inserir nos Termos de Referência para os Estudos de Impacto } \\
\text { que antecedem as obras, indicadores referentes aos direitos de } \\
\text { crianças e adolescentes e suas famílias (no curto e longo pra- } \\
\text { zo), visando condicionalidades específicas para o financiamen- } \\
\text { to e licenciamento" (Idem). }\end{array}$ \\
\hline
\end{tabular}




\begin{tabular}{|c|c|}
\hline $\begin{array}{c}\text { Carta de Porto } \\
\text { Velho } \\
\text { (CNEVSCA, 2011) }\end{array}$ & $\begin{array}{l}\text { "Estabelecer, no processo de licenciamento e contratação, } \\
\text { protocolo de prevenção às violações de direitos humanos de } \\
\text { crianças e adolescentes a ser seguido pelos empreendimentos } \\
\text { e setor público e sob monitoramento do Sistema de Garantia de } \\
\text { Direitos" (p. 4). } \\
\text { "Garantir que a sociedade, sobretudo as comunidades atingi- } \\
\text { das, tenham acesso às informações sobre o processo de licen- } \\
\text { ciamento e sobre os impactos que as grandes obras e os mega- } \\
\text { eventos trarão às localidades" (Idem). }\end{array}$ \\
\hline $\begin{array}{c}\text { Exploração } \\
\text { Sexual e } \\
\text { Grandes Obras } \\
\text { (CHILDHOOD, } \\
\text { 2011) }\end{array}$ & $\begin{array}{l}\text { "Inserir no marco regulatório - particularmente licenciamen- } \\
\text { to ambiental - e nas linhas de financiamento e cláusulas que } \\
\text { prevejam investimentos em montantes suficientes para com- } \\
\text { pensar os impactos decorrentes da implantação dos grandes } \\
\text { projetos públicos ou privados" (p. 14). } \\
\text { "Ser transparente e prestar contas à população sobre os inves- } \\
\text { timentos relacionados à compensação social do empreendedor. } \\
\text { Deve-se observar em tal prestação de contas tanto a adequada } \\
\text { destinação dos recursos quanto a lisura com que estes são des- } \\
\text { pendidos, tanto por atores privados quanto públicos" (p. 15). } \\
\text { "Estar presente no território, na etapa de planejamento da } \\
\text { obra, o órgão licenciador, fazendo diagnósticos que permitam } \\
\text { compensar os impactos, ou seja, não basta que um terceiro faça } \\
\text { isso, pois compete ao Estado estar no território, realizando } \\
\text { essa avaliação diagnóstica" (Idem). } \\
\text { "Qualificar o olhar e os instrumentos do IBAMA para as ques- } \\
\text { tões de violência sexual contra crianças e adolescentes" (Idem). } \\
\text { "Obedecer o licenciamento a uma lógica intersetorial, de forma } \\
\text { a mensurar com maior acuidade os impactos" (Idem). } \\
\text { "Desenvolver estratégias efetivas de comunicação que possam } \\
\text { informar as comunidades sobre todos os impactos decorrentes } \\
\text { da obra" (Idem). } \\
\text { "Assegurar no licenciamento ambiental a obrigatoriedade } \\
\text { da realização de monitoramento das violações de direito de } \\
\text { crianças e adolescentes ao longo de todo o período de execu- } \\
\text { ção das obras" (p. 17). } \\
\text { "Assegurar a efetiva participação das universidades ao longo do } \\
\text { processo de licenciamento e de execução das obras (tais ins- } \\
\text { tituições devem contribuir particularmente com o desenvolvi- } \\
\text { mento de indicadores)" (Idem). } \\
\text { "Criar estratégias de comunicação relativas aos impactos so- } \\
\text { ciais ambientais, que dêem visibilidade aos mesmos" (Idem). } \\
\text { "Considerar, no estudo de impacto ambiental e no relatório de } \\
\text { impacto sobre o meio ambiente, o contexto social, econômico e } \\
\text { cultural onde a obra está sendo realizada (Idem). } \\
\text { "Explicitar, no Projeto Básico Ambiental, a necessidade de cam- } \\
\text { panhas contínuas sobre ESCA para os trabalhadores" (p. 18). }\end{array}$ \\
\hline
\end{tabular}




\begin{tabular}{|c|c|}
\hline $\begin{array}{c}\text { Carta } 18 \text { de } \\
\text { maio } \\
(\text { CNEVSCA, 2012) }\end{array}$ & $\begin{array}{l}\text { "Demandamos que os processos de licenciamento destes em- } \\
\text { preendimentos incorporem, na análise dos impactos sobre o } \\
\text { meio socioeconômico, o princípio constitucional da absolu- } \\
\text { ta prioridade à proteção integral dos direitos de crianças e } \\
\text { adolescentes (art.227, Constituição da República e Resolu- } \\
\text { ção } 001 / 86 \text { do CONAMA), com o fito de não permitir que tais } \\
\text { empreendimentos sejam licenciados sem a análise devida dos } \\
\text { impactos sociais negativos e que, em sendo licenciados, o pla- } \\
\text { no de mitigação ressalte a prioridade dos direitos da criança e } \\
\text { do adolescente" (p. 2). }\end{array}$ \\
\hline $\begin{array}{l}\text { Pacto CONANDA } \\
\text { (CONANDA, } \\
\text { 2012) }\end{array}$ & $\begin{array}{l}\text { "garantir através do alinhamento do plano decenal com pro- } \\
\text { gramas e projetos do plano básico ambiental recursos para in- } \\
\text { fância e adolescência, através do FIA e dos fundos das políticas } \\
\text { setoriais" (p. 1). }\end{array}$ \\
\hline $\begin{array}{c}\text { Carta de } \\
\text { Altamira } \\
(\mathrm{CNEVSCA}, 2013)\end{array}$ & $\begin{array}{l}\text { "Incidência do princípio constitucional da prioridade absolu- } \\
\text { ta nos EIA's por meio da exigência de elaboração de estudos } \\
\text { e continuados da realidade e projeção de impactos à infância } \\
\text { e adolescência, com definição de investimentos que garantam } \\
\text { a sustentabilidade das condições sociais de vida das crianças } \\
\text { e dos adolescentes antes, durante e depois da construção das } \\
\text { grandes obras de infraestrutura e apropriação dos recursos } \\
\text { naturais, além da elaboração de Relatório de Impacto sobre o } \\
\text { Meio Ambiente (RIMA) em linguagem adequada e acessível à } \\
\text { compreensão de crianças e adolescentes" (p. 2-3). } \\
\text { "Modificação do modelo de audiências públicas destinado às } \\
\text { populações locais tornando-o de caráter deliberativo e que } \\
\text { utilize metodologia adequada para a participação social e o di- } \\
\text { álogo entre os sujeitos interessados, além da obrigatória pro- } \\
\text { moção de audiências públicas nos espaços de protagonismo } \\
\text { infanto-adolescente, como a escola, os centros de recreação, } \\
\text { entre outros locais" (p. 3). } \\
\text { "Incidência dos planos e dos diagnósticos dos Conselhos Mu- } \\
\text { nicipais de Controle Social, em especial do Conselho Municipal } \\
\text { dos Direitos da Criança e do Adolescente (CMDCA), na defini- } \\
\text { ção do conteúdo das condicionantes socioambientais e demais } \\
\text { políticas compensatórias" (Idem). } \\
\text { "Responsabilização econômica das empresas e governos envolvi- } \\
\text { dos por meio da destinação de, no mínimo, 30\% (trinta por cento) } \\
\text { do recurso econômico total das grandes obras para ser utilizado } \\
\text { na execução das condicionantes e demais políticas compensató- } \\
\text { rias, definindo setor específico de condicionantes voltadas para a } \\
\text { melhoria das condições de vida das crianças e dos adolescentes, } \\
\text { assim como ocorre com os povos indígenas" (p. 4). }\end{array}$ \\
\hline
\end{tabular}


Há um importante esforço de identificação das comunidades locais e, particularmente, das crianças e dos adolescentes na condição de sujeitos de direitos individuais e coletivos com força político-jurídica de demandar determinadas prestações e condutas (ABRAMOVICH, 2004) por parte do Estado e das empresas envolvidas no âmbito do licenciamento ambiental.

Às crianças e aos adolescentes o eixo central da força político-jurídica está no mecanismo hermenêutico de filtragem constitucional do licenciamento ambiental à luz do paradigma da proteção integral, de modo a instituir a obrigatoriedade da adoção do princípio jurídico da prioridade absoluta das crianças e dos adolescentes - inscrito no artigo 227 da CF/88 e regulamentado pelo artigo 4o12 do ECA - como "parâmetro de revisão" dos órgãos, procedimentos e instrumentais do licenciamento ambiental, não apenas para assegurar a proteção dos direitos de crianças e adolescentes, mas para transformá-los - ou adequá-los - mediante a incidência do seu conteúdo.

Concordando com Silveira e Veronese (2015), que estabelecem a semelhança conceitual entre o princípio constitucional da prioridade absoluta e o princípio internacional do melhor (ou do superior) interesse da criança - estabelecido no artigo 3oㅡ, inciso 1, da Convenção dos Direitos da Criança (CDC) da ONU - é possível complementar a abordagem contida nos documentos analisados com aquele presente no Comentário Geral no. . 16/2013 do Comitê dos Direitos da Criança da ONU, quando estabelece orientação à internalização do melhor interesse da criança nas atividades econômicas:

El artículo 3, párrafo 1, de la Convención establece que una consideración primordial de los Estados en todas las medidas concernientes a los niños será el interés superior del niño. Los Estados están obligados a integrar y aplicar este principio en todos los procedimientos legislativos, administrativos y judiciales relativos a las actividades y operaciones empresariales que afecten directa o indirectamente a los niños. Por ejemplo, los Estados deben garantizar que el interés superior del niño ocupe un lugar central en la elaboración de las leyes y las políticas que determinan las actividades y operaciones empresariales, como las relativas al empleo, la fiscalidad, la corrupción, la privatización, el transporte y otras cuestiones económicas, comerciales o financieras generales (ONU, 2013, p. 6). 
A confluência dos princípios jurídicos estabelece a base de legitimação das mudanças na totalidade dos elementos que compõe o licenciamento ambiental - desde o termo de referência do EIA até o termino operacional do empreendimento - a fim de, num primeiro momento, adequá-lo às exigências hermenêutico-normativas dos direitos das crianças e dos adolescentes (OLIVEIRA, 2014b) e, num segundo momento, torná-lo passível de acionamento judicial (e extrajudicial) em caso de não cumprimento ou violação (OLIVEIRA, 2016).

Em paralelo, há a compreensão de que o atendimento às questões que envolvem crianças e adolescentes extrapola a capacidade institucional dos órgãos ambientais e demanda a internalização, na dinâmica do licenciamento ambiental, de outro fundamento estrutural da política de atendimento da criança e do adolescente, o da intersetorialidade ${ }^{13}$, buscando, com isso, ressaltar a necessidade de "articulação de saberes e experiências no planejamento, realização e avaliação de ações destinadas a alcançar efeito sinérgico em situações complexas" (DRAIBE, 2015, p. 489) ou de natureza multidimensional, como questões sociais relativas às crianças e aos adolescentes.

Assim, as proposições fixam-se no imperativo da intersetorialidade para promover a coordenação dos órgãos do campo ambiental com órgãos públicos que tenham maior propriedade de intervenção sobre a temática das crianças e dos adolescentes, instituindo novas ações complementares no licenciamento ambiental, de modo a qualificar as formas de tratamento da questão infanto-adolescente, atentando, também, para a devida participação da sociedade civil e do controle social.

Para o reforço do caráter obrigacional das demandas apresentadas, há uma interligação do princípio jurídico da prioridade absoluta com a compreensão da "sustentabilidade das condições sociais de vida de crianças e adolescentes" (CNEVSCA, 2013, p. 2) enquanto tradução do "direito de toda criança a um nível de vida adequado ao seu desenvolvimento físico, mental, espiritual, moral e social", tal como estabelece o artigo 27 da CDC, de modo a inserir nos direitos das crianças o paradigma da sustentabilidade. Com isso, ampliando os aspectos normativos do direito ao nível de vida adequado ante a incorporação dos elementos 
econômicos e ambientais próprios do desenvolvimento sustentável ${ }^{14}$, ao mesmo tempo em que sinaliza, tal como preceitua Parkman (1999), a ampliação do investimento no capital humano como garantia de níveis de vida adequados e de distribuição social do crescimento econômico.

Para materialização das proposições, a REVSCA propõe a articulação entre o CONANDA e o Conselho Nacional de Meio Ambiente (CONAMA), a fim de estabelecer uma resolução conjunta dos órgãos que regulamente a "definição de diretrizes que internalizem a proteção integral dos direitos da criança e do adolescente no licenciamento ambiental (EIA-RIMA) e nas etapas da licença e das audiências públicas do licenciamento" (CNEVSCA, 2014). Certamente, a aposta na incidência sobre o controle social justifica-se pelo fato do CONAMA, por meio da Resolução no. 237/1997, regulamentar e fiscalizar o licenciamento ambiental, sendo importante a reformulação dos preceitos contidos nessa Resolução para melhor internalização dos direitos humanos na identificação, prevenção e reparação dos danos socioambientais e dos investimentos socioeconômicos existentes nos grandes empreendimentos.

\section{Responsabilização jurídica das empresas}

O neodesenvolvimentismo econômico brasileiro acirrou um processo relativamente recente de transferência da incumbência da construção e execução de grandes empreendimentos, via licitações e concessões públicas, para empresas de abrangência nacional ou transnacional (PASIN, BORGES, 2003) e que passam também a receber empréstimos financeiros provenientes, principalmente, do Banco Nacional de Desenvolvimento Econômico e Social (BNDES), entre outros bancos públicos ${ }^{15}$.

A dinâmica de afetação das atividades empresariais nas populações circunscritas à área de influência dos grandes empreendimentos é de abrangência e intensidade de escalas difíceis - para não dizer impossíveis - de serem traduzidas em cálculos financeiros de caráter mitigatório, e cuja fiscalização pelos órgãos ambientais, especialmente o IBAMA, e órgãos financeiros, como o BNDES, não é feito com o rigor e regulação necessários, e tampouco apresenta diretrizes de monitoramento e de investimento alinhados com os preceitos dos direitos das crianças e dos adolescentes. 
Ante tal formato de intervenção empresarial e de fomento/controle estatal, a REVSCA coloca a necessidade de rediscutir o papel do Estado no controle e condicionamento da ação empresarial e de tencionar pela radicalização da relação entre direitos humanos e empresas para internalização de diretrizes de direitos das crianças e dos adolescentes, e de direitos humanos em geral, não enquanto estratégias de marketing empresarial, mas como política corporativa fundamental, conforme se pode identificar no quadro (Quadro 3) abaixo.

\section{Quadro 3. Sistematização das proposições}

\begin{tabular}{|c|c|}
\hline Documentos & Conteúdo \\
\hline $\begin{array}{c}\text { Carta de Porto } \\
\text { Velho } \\
\text { (CNEVSCA, } \\
2011)\end{array}$ & $\begin{array}{l}\text { "Garantir a transparência da destinação de recursos, tanto por } \\
\text { parte dos órgãos públicos, quanto do setor empresarial, assegu- } \\
\text { rando a participação popular" (p. 4). } \\
\text { "Estabelecer, no processo de licenciamento e contratação, proto- } \\
\text { colo de prevenção às violações de direitos humanos de crianças e } \\
\text { adolescentes a ser seguido pelos empreendimentos e setor público } \\
\text { e sob monitoramento do Sistema de Garantia de Direitos" (Idem). } \\
\text { "Garantir, em longo prazo, que as riquezas geradas pelos empre- } \\
\text { endimentos possam ser revertidas em favor das comunidades, } \\
\text { respeitando a cultura local, por meio da implantação e implemen- } \\
\text { tação de políticas públicas e de fundos de reparação" (Idem). }\end{array}$ \\
\hline $\begin{array}{c}\text { Exploração } \\
\text { Sexual e } \\
\text { Grandes Obras } \\
\text { (CHILDHOOD, } \\
\text { 2011) }\end{array}$ & $\begin{array}{l}\text { "As empresas devem destinar recursos da compensação social } \\
\text { para que a sociedade civil desenvolva ações de fortalecimento do } \\
\text { controle social" (p. 16). } \\
\text { "Desenvolver projetos de controle social destinado às verbas } \\
\text { compensatórias" (Idem). } \\
\text { "Acompanhar o investimento das compensações sociais criando } \\
\text { formas para averiguar o volume de recursos que os empreendi- } \\
\text { mentos investem em rubricas de compensações sociais" (Idem). } \\
\text { "Capacitar e qualificar as entidades da sociedade civil e as lide- } \\
\text { ranças sociais, ou seja, instituir estratégias para viabilizar o for- } \\
\text { talecimento de pessoas e instituições da sociedade civil, no pro- } \\
\text { cesso que antecede o licenciamento, depois do licenciamento e } \\
\text { acompanhamento da execução das obras" (Idem). }\end{array}$ \\
\hline
\end{tabular}




\begin{tabular}{|c|c|}
\hline $\begin{array}{c}\text { Exploração } \\
\text { Sexual e } \\
\text { Grandes Obras } \\
\text { (CHILDHOOD, } \\
\text { 2011) }\end{array}$ & 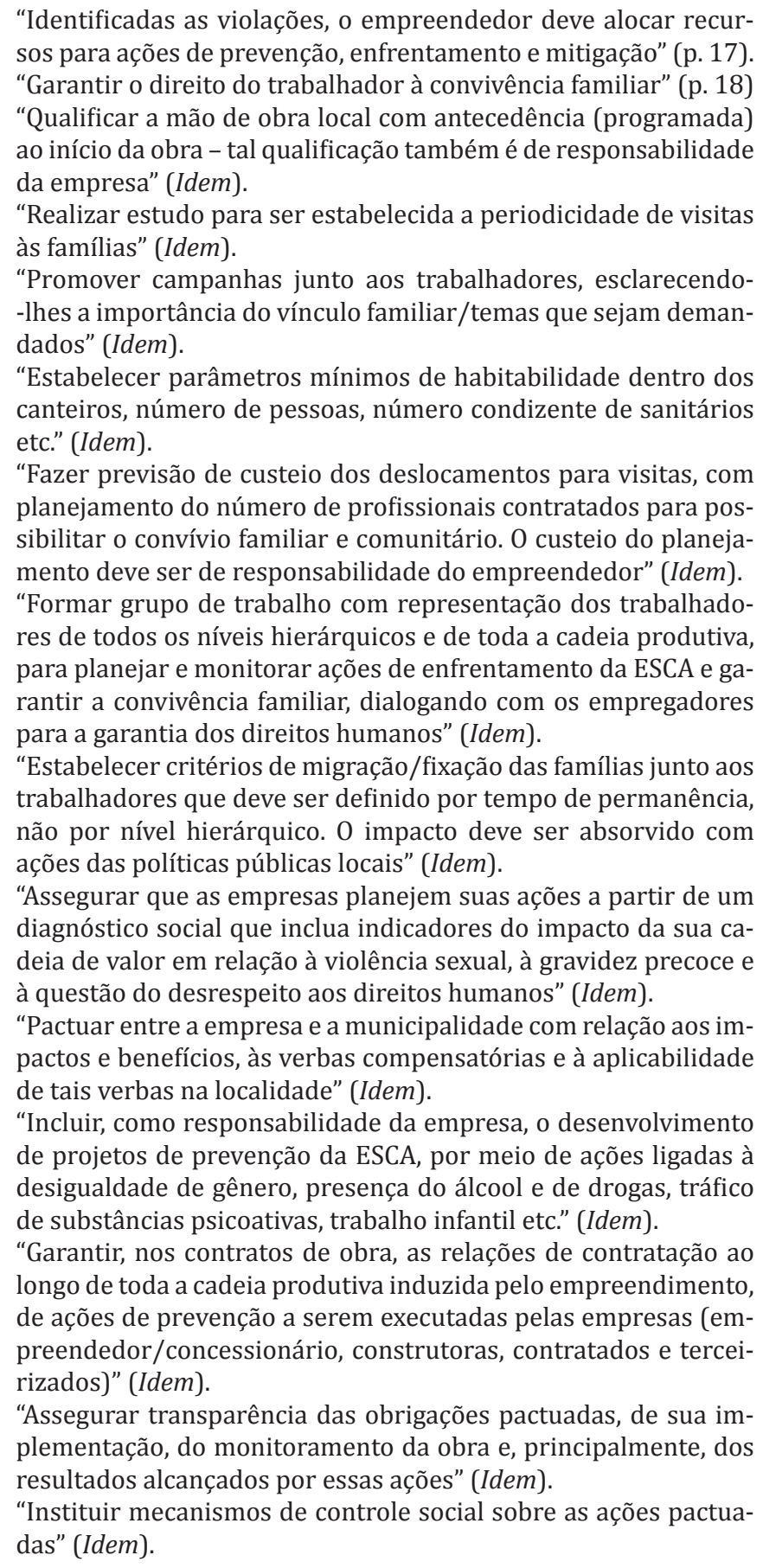 \\
\hline
\end{tabular}




\begin{tabular}{|c|c|}
\hline $\begin{array}{c}\text { Exploração } \\
\text { Sexual e } \\
\text { Grandes Obras } \\
\text { (CHILDHOOD, } \\
\text { 2011) }\end{array}$ & $\begin{array}{l}\text { "Fortalecer as redes de proteção e do sistema de garantia de di- } \\
\text { reitos existentes" (Idem). } \\
\text { "Realizar estudo de viabilidade para inserção socioprodutiva dos } \\
\text { jovens da localidade" (Idem). } \\
\text { "Fazer cumprir pelas empresas os planos nacionais, estaduais ou } \\
\text { municipais, pactuados nas diferentes políticas públicas" (Idem). } \\
\text { "Executar as ações de prevenção da ESCA, de responsabilidade } \\
\text { das empresas, por meio de parcerias com as instituições locais, } \\
\text { sejam elas governamentais ou da sociedade civil. Tal provisão } \\
\text { consiste em uma estratégia de fortalecimento de tais institui- } \\
\text { ções, de modo que elas se fortaleçam e possam atuar no período } \\
\text { de operação do empreendimento" (Idem). } \\
\text { "Destinar recursos das empresas ou consórcios, além das verbas } \\
\text { compensatórias, aos fundos municipais da criança e do adoles- } \\
\text { cente, como elemento de fortalecimento dessas estruturas da } \\
\text { localidade" (Idem). } \\
\text { "Disponibilizar informações sobre os impactos, as ações propos- } \\
\text { tas, os resultados esperados, de forma que as informações sejam } \\
\text { apropriadas pelas comunidades locais" (Idem). } \\
\text { "Fortalecer a economia local, com absorção da mão de obra lo- } \\
\text { cal e de toda a cadeia produtiva existente, quando da execução } \\
\text { da obra" (Idem). "Fazer um pacto em que conste, no contrato de } \\
\text { trabalho, o compromisso das empresas e dos trabalhadores com } \\
\text { a prevenção e enfrentamento da ESCA" (p. 19). }\end{array}$ \\
\hline $\begin{array}{c}\text { Carta } 18 \text { de } \\
\text { maio } \\
\text { (CNEVSCA, } \\
2012)\end{array}$ & $\begin{array}{l}\text { "Da mesma forma, reivindicamos que as agências de financia- } \\
\text { mento (BNDES, BB, CEF) criem regras e protocolos específicos, } \\
\text { com a participação da sociedade civil e comunidade, para as- } \\
\text { segurar por meio de condicionalidades contratuais os direitos } \\
\text { humanos das comunidades atingidas, a fim de que os empreen- } \\
\text { dimentos não venham causar danos a essas populações, espe- } \\
\text { cialmente crianças e adolescentes" (p. 2). } \\
\text { "Demandamos imediata adoção de iniciativas de responsabili- } \\
\text { zação e reparação dos direitos violados, chamando ao processo } \\
\text { de reparação os atores públicos e privados responsáveis por tais } \\
\text { violações, incluindo a responsabilidade civil coletiva dos envol- } \\
\text { vidos" (p. 2-3). }\end{array}$ \\
\hline $\begin{array}{c}\text { Pacto } \\
\text { CONANDA } \\
\text { (CONANDA, } \\
\text { 2012) }\end{array}$ & $\begin{array}{l}\text { "Criar mecanismo que determinem que as empresas das grandes } \\
\text { obras destinem recursos para o FIA municipal" (p. 4). }\end{array}$ \\
\hline
\end{tabular}




\begin{tabular}{|c|c|}
\hline $\begin{array}{c}\text { Carta de } \\
\text { Altamira } \\
\text { (CNEVSCA, } \\
\text { 2013) }\end{array}$ & $\begin{array}{l}\text { "Registro, no Conselho Municipal dos Direitos da Criança e do } \\
\text { Adolescente, das empresas envolvidas com o desenvolvimento } \\
\text { de políticas compensatórias que afetem crianças e adolescentes, } \\
\text { com obrigação de encaminhar relatório de avaliação das ativida- } \\
\text { des e de prestação de conta dos recursos investidos no municí- } \\
\text { pio" (p. 03). } \\
\text { "Quebra do monopólio fiscalizador das grandes obras de infra- } \\
\text { estrutura e de apropriação dos recursos naturais pelos órgãos } \\
\text { competentes da esfera ambiental (IBAMA e secretarias de meio } \\
\text { ambiente) mediante o alargamento da fiscalização para todos os } \\
\text { Conselhos Setoriais, com repasse permanente de relatórios de } \\
\text { cumprimento das condicionantes pelas empresas responsáveis } \\
\text { para monitoramento" (Idem). }\end{array}$ \\
\hline
\end{tabular}

As proposições organizam-se sobre o binômio da obrigação empresarial radicado na assertiva de que tanto os territórios devem ser mais bem preparados (ou fortalecidos) para a implantação dos empreendimentos, quanto os empreendimentos precisam ser mais bem estruturados (ou reorganizados) para implantação nos territórios. Nesse sentido, mudanças no panorama territorial e nas atividades econômicas tornam-se linhas prioritárias de interlocução entre direitos humanos e empresas.

Ambas as facetas possuem uma base comum de fundamentação jurídica estabelecida, internacionalmente, nos Princípios Orientadores sobre Empresas e Direitos Humanos (POEDH) da ONU, com ênfase ao artigo 11 que aduz o dever das empresas de respeitarem os direitos humanos e de "se abster de infringir os direitos humanos de terceiros e enfrentar os impactos negativos sobre os direitos humanos nos quais tenham algum envolvimento" (CONECTAS, 2012, p. 10).

Sob a lógica do respeito aos direitos humanos, definem-se responsabilidades jurídicas às empresas de não apenas evitar empreender ações que violem direitos humanos (regra de não fazer ou prestação negativa), como devem estabelecer medidas que atuem na identificação, prevenção, mitigação e reparação de direitos humanos (regra de fazer ou prestação positiva) ${ }^{16}$, portanto, no controle dos impactos aos direitos humanos que suas atividades econômicas podem produzir ou acirrar.

De acordo com Gerber, Kyriakakis e O'Byrne (2013), os POEDH/ ONU foram fundamentais para melhor estruturar a relação entre direitos humanos e empresas, mas não se trata de um documento fechado 
em si, antes sim algo que precisa ser refinado e adaptado à uma ampla variedade de negócios, e aos contextos em que eles operam, assim como às especificidades de direitos humanos que podem afetar. Daí advém a afirmação de que os POEDH/ONU não são o "começo do fim" da abordagem de direitos humanos e empresas, mas sim o "fim do começo", um primeiro apanhado de regras gerais que necessitam de novos elementos para aperfeiçoar o respeito empresarial pelos direitos humanos.

O campo internacional dos direitos das crianças e dos adolescentes foi um dos que mais avançou na formulação de medidas que ampliem a relação entre direitos das crianças e práticas empresariais. Primeiro, com a elaboração do documento "Direitos das Crianças e Princípios Empresariais”, pelo Fundo das Nações Unidas pela Infância (UNICEF), em 2012, contendo 10 princípios de orientação às empresas para respeito aos direitos das crianças, e depois com a elaboração do Comentário Geral no. 16, pelo Comitê dos Direitos da Criança da ONU, em que há a interpretação da aplicação da CDC para a regulação, operação, fiscalização e responsabilização das práticas empresariais. Ambos os documentos foram fortemente influenciados pelos POEDH/ONU na estruturação de seus conteúdos.

No Brasil, trabalha-se com a hermenêutica jurídica do paradigma constitucional da proteção integral, inscrito no artigo 227 da CF/88, para indicar que nos agentes expressamente definidos como responsáveis pela garantia da proteção integral aos direitos às crianças e aos adolescentes, é dizer, "a família, a sociedade e o Estado", há a inserção das empresas como parte da sociedade, logo, também obrigadas a promover e proteger tais direitos (GDHEE, 2013; GVCES, 2013; OLIVEIRA, 2014b). Por isso, o binômio da responsabilização jurídica das empresas é, no fundo, a visualização do panorama integral da assunção das empresas como membros da rede de proteção às crianças e aos adolescentes, na observância dos paradigmas constitucionais da proteção integral e da prioridade absoluta.

A partir dessa fundamentação jurídica, é preciso aprofundar o binômio da responsabilização jurídica das empresas presente nos documentos REVSCA para discutir de maneira separada suas implicações para o campo dos direitos humanos. 
O primeiro deles, de preparação dos territórios para a implantação dos empreendimentos, é sinalizado nos documentos por um conjunto de proposições que objetivam responsabilizar as empresas para promoção de medidas que garantam o fortalecimento das políticas públicas, do controle social e da sociedade civil dos territórios afetados por seus empreendimentos, ou, como sintetizado num dos documentos, de "fortalecer as redes de proteção e do sistema de garantia de direitos existentes" (CHILDHOOD, 2011, p. 18).

Tais medidas envolveriam, basicamente, o investimento em recursos financeiros (ou compensações sociais), qualificação técnica aos agentes locais, cumprimento de objetivos traçados em planos intersetoriais e estabelecimento de parcerias com instituições públicas para execução de ações preventivas, entre outras questões, gerando um dever de prestações positivas semelhantes ao estabelecido no Comentário Geral no . 16/2013:

"33. Las empresas y las organizaciones sin fines de lucro pueden contribuir a la prestación y la gestión de servicios, como el abastecimiento de agua salubre, el saneamiento, la educación, el transporte, la salud, los cuidados alternativos, el suministro energético, la seguridad y los centros de detención, que son fundamentales para el disfrute de los derechos del niño. El Comité no establece la forma de provisión de estos servicios, pero es importante destacar que los Estados no están eximidos del cumplimiento de las obligaciones que han asumido en virtud de la Convención cuando externalicen o privaticen servicios que afecten a la efectividad de los derechos del niño...

34. Los Estados deben adoptar medidas concretas que tengan en cuenta la participación del sector privado en la prestación de servicios a fin de velar por que los derechos enumerados en la Convención no se vean comprometidos. Tienen la obligación de establecer normas, con arreglo a la Convención, y de vigilar de cerca su cumplimiento. Una supervisión, vigilancia o inspección inadecuadas por parte de estos órganos puede dar lugar a graves violaciones de los derechos del niño, como la violencia, la explotación o el descuido" (ONU, 2013, p. 11).

Tudo isso acaba germinando, como pano de fundo, a problematização de se as empresas têm, de fato, a competência de atuar para a operacionalização e o fortalecimento das políticas públicas e da sociedade local, especialmente no campo dos direitos das crianças e dos adolescentes? 
Desde a ótica das empresas, a resposta é sim, fundamentada na compreensão de que as atividades empresariais podem produzir ou acirrar impactos aos direitos humanos em determinado território que extrapolam a capacidade interventiva do Estado, cabendo às empresas assumirem graus de responsabilidade e, portanto, de amplitude de investimento segundo o critério, estabelecido no POEDH/ONU, da "esfera de influência", assim definido no artigo 14:

A responsabilidade das empresas de respeitar os direitos humanos aplica-se a todas as empresas independentemente de seu tamanho, setor, contexto operacional, proprietário e estrutura. No entanto, a magnitude e a complexidade dos meios dispostos pelas empresas para assumir essa responsabilidade pode variar em função desses fatores e da gravidade dos impactos negativos das atividades da empresa sobre os direitos humanos" (CONECTAS, 2012, p. 11).

A "esfera de influência" é um critério de dosimetria da responsabilização jurídica das empresas que indica que quanto maior o potencial ou a efetiva violação aos direitos humanos pelas práticas empresariais desenvolvidas, assim como a influência em relação aos seus funcionários, cadeia produtiva e território de implantação do empreendimento, maior também devem ser os meios a serem assumidos pela empresa para atuar na identificação, prevenção, mitigação e reparação dessas violações.

Portanto, em cenários de grandes empreendimentos, necessariamente relacionados a volumosos investimentos de recursos humanos e financeiros para sua operacionalização, há uma "esfera de influência" de relevante magnitude que deve ser correspondida com uma responsabilização considerável das empresas envolvidas para com os impactos aos direitos humanos que possam causar ou influenciar.

Por outro lado, desde a lógica do Estado, do controle social e da sociedade civil, ainda que se possa reiterar o "sim" (com aspas), deve-se atentar para os riscos que isto pode ocasionar em se tratando de intervenção realizada por agente privado que possui lógica própria de lidar com os recursos e as políticas a serem desenvolvidas. Portanto, há de se considerar a importância da manutenção do gerenciamento das ações como prerrogativa de execução e fiscalização do Estado, com apoio do 
controle social e da sociedade civil, só cabendo às empresas o papel de financiarem e, quando muito, de assessorarem técnica aspectos específicos de sua execução, mas evitando que seu poder econômico implique em influências políticas no planejamento, execução e avaliação das políticas públicas e das ações sociais.

Ainda assim, na prática, a "esfera de influência" dos impactos das atividades empresariais torna-se, quase sempre, proporcional ao grau de influência política das empresas, ainda mais em cenários de implantação de grandes empreendimentos em territórios com histórica ausência ou deficiência da atuação estatal na promoção dos direitos sociais básicos e, por isso mesmo, quando estes passam a ser direcionados para cumprimento enquanto condicionantes socioambientais das licenças ambientais dos empreendimentos (Oliveira, 2013), portanto, deslocando-se para serem custeadas e, por vezes, operacionalizadas pelo empreendedor, no caso, as empresas.

Em tais cenários, é ainda mais necessário fortalecer a autonomia do Estado, do controle social e da sociedade civil perante os agentes privados, com a adoção de medidas que reequilibrem a correlação de forças entre os envolvidos e canalizem a participação empresarial para aspectos positivos ligados à promoção dos direitos humanos, em especial dos direitos das crianças e dos adolescentes, mediante a colaboração empresarial com as políticas públicas, e não a privatização destas (KLIKSBERG, 2010). Para tanto, especial atenção deve ser dada à capacidade do controle social e da sociedade civil conduzir o monitoramento permanente das ações empreendidas pelo Estado e pelas empresas, de modo a denunciar possíveis situações de predomínio de interesses particulares nos espaços e interesses públicos, passível de acionamentos judiciais e extrajudiciais.

A segunda parte do binômio de síntese das proposições presentes nos documentos da REVSCA - identificada na assertiva de que os empreendimentos também precisam se reestruturar para implantação nos territórios - sinaliza a incidência dos preceitos existentes nos conteúdos dos direitos das crianças e dos adolescentes para reconfiguração de aspectos internos das práticas empresariais, tal qual já visto na análise do licenciamento ambiental. 
Aqui é a própria lógica de operação empresarial que está em disputa, buscando redefini-la para ampliar a capacidade de identificação, prevenção, mitigação e/ou reparação aos direitos humanos. Para tanto, a incidência da prioridade absoluta da criança e do adolescente, assim como de suas condições de sujeitos de direitos em condição peculiar de desenvolvimento ${ }^{17}$ - portanto, em condições mais vulneráveis de afetação negativa de seus direitos pelas práticas empresariais ligadas aos grandes empreendimentos - são materializadas via proposições relacionadas a diversas etapas do planejamento e da operação empresarial.

Do conjunto das proposições, ressaltam-se três questões de maior importância estrutural para o condicionamento das práticas empresariais aos ditames dos direitos humanos.

A primeira, sintetizada na proposição de "que as empresas planejem suas ações a partir de um diagnóstico social" (CHILDHOOD, 2011, p. 18), traduzido, numa linguagem de direitos humanos e empresas, enquanto a obrigação empresarial de desenvolver auditoria (due diligence) em direitos humanos de maneira prévia à instalação dos empreendimentos para diagnosticar os impactos que possa ter sua instalação e operação às condições de vida no território afetado e estabelecer medidas de prevenção, mitigação e/ou reparação, tal como regulamenta o artigo 17 do $\mathrm{POEDH} / \mathrm{ONU}$ :

A fim de identificar, prevenir, mitigar e reparar os impactos negativos de suas atividades sobre os direitos humanos, as empresas devem realizar auditorias (due diligence) em matéria de direitos humanos. Esse processo deve incluir uma avaliação do impacto real e potencial das atividades sobre os direitos humanos, a integração das conclusões e sua atuação a esse respeito; o acompanhamento das respostas e a comunicação de como as consequências negativas são enfrentadas" (CONECTAS, 2012, p. 12).

A auditoria em direitos humanos realizada pela empresa corre em paralelo e, preferencialmente, antes dos estudos específicos do licenciamento ambiental. Pode ser inserida no âmbito mais amplo das avaliações de risco empresarial, desde que "não se limitem a identificar e gerenciar riscos importantes para a própria empresa, senão que incluam os riscos para os titulares de direitos" (CONECTAS, 2012, p. 12). 
No campo dos direitos das crianças e dos adolescentes, necessita estabelecer a coleta de dados e a produção de indicadores que reflitam as violações pré-existentes no contexto do território a ser afetado e aquelas que possam ser geradas/impulsionadas pela dinâmica do empreendimento, o que exige uma abertura de interlocução com agentes locais, especialmente da rede de proteção, para melhor compreensão das implicações da prática empresarial para o território e os direitos humanos.

Dessa auditoria espera-se que não apenas sinalize ações para atuação junto à população do território afetado, com foco prioritário em crianças e adolescentes, mas que também proponha modificações na dinâmica empresarial, com capacidade de incidir nos setores estratégicos da empresa e em sua cadeia produtiva. Tampouco pode se tratar de uma auditoria pontual, mas de algo continuado que acompanhe o desenvolvimento do empreendimento e consiga identificar e propor formas de intervenção, inclusive de responsabilização judicial, aos impactos potenciais e reais aos direitos humanos que forem se projetando durante o ciclo de vida do empreendimento.

A segunda questão está relacionada às condições de vida dos trabalhadores dos empreendimentos, portanto, dos funcionários das empresas como questão central para a redução ou ampliação dos riscos aos direitos de crianças e adolescentes. Isto envolve discutir tanto a qualidade do ambiente de trabalho que, em locais de grandes empreendimentos, acaba se revestindo, também, em ambientes de moradia dos trabalhadores, quanto à migração populacional impulsionada pelo grande empreendimento, majoritariamente de pessoas do gênero masculino (RIBEIRO, 2014).

Nesse caso, discutir a política empresarial de habitação, de lazer e de convivência familiar, assim como a prioridade de qualificação e contratação de mão de obra local, articulada ou não com parcerias estatais e/ou sociais, é discutir indiretamente mecanismos de proteção aos direitos das crianças e dos adolescentes, pois podem resultar num menor envolvimento da dinâmica empresarial com situações que coloquem em risco as condições de vida de crianças e adolescentes, sem descuidar do contexto mais amplo de afetação às suas famílias e comunidades.

Por fim, a terceira questão está na implicação de obrigações às agências de financiamento, como o BNDES, o Banco do Brasil (BB) e a Caixa 
Econômica Federal (CEF), para que "criem regras e protocolos específicos... para assegurar... condicionalidades contratuais [de respeito aos] direitos humanos das comunidades atingidas... especialmente crianças e adolescentes" (CNEVSCA, 2012, p. 2).

Estrategicamente algumas das reivindicações da REVSCA são direcionadas aos bancos públicos, em especial o $\mathrm{BNDES}^{18}$, justamente pelo papel decisivo que assumiram na execução financeira do neodesenvolvimentismo brasileiro e, com isso, o potencial de influência que possuem para disseminar o respeito aos direitos humanos pelas empresas financiadas.

Assim, tem-se horizonte de problematização - e de disputa - do papel das agências de financiamento na internalização dos direitos humanos pelas empresas, assim como dos instrumentais que podem ser construídos ou adaptados para servirem a tal propósito, engendrando o olhar atento de tais agencias para o desenvolvimento social dos territórios alvo do investimento procedente de seus apoios, assim como da capacidade de controle de impactos mediante a adoção de critérios de restrição e/ou de monitoramento contratual. Isto exige, por correlato, uma abertura para o diálogo permanente e horizontal com agentes locais e auditorias independentes, assim como o reconhecimento da prioridade absoluta da garantia dos direitos de crianças e adolescentes como preceito de adequação dos bancos e das práticas empresariais.

\section{PARTICIPAÇÃO SOCIAL E PROTAGONISMO INFANTO- ADOLESCENTE NOS ESPAÇOS DE DECISÃO DOS GRANDES EMPREENDIMENTOS}

As condições de participação social nos cenários de implantação de grandes empreendimentos foram historicamente marcadas por uma ausência ou ineficiência de espaços públicos que permitam a incidência dos sujeitos e grupos locais, e de seus posicionamentos no planejamento, na execução e na fiscalização das atividades produtivas, tornando visível a assimetria das relações de poder existente entre o Estado, as empresas e a sociedade, nesta última com especial atenção à população afetada. 
Mais do que explicitar a reprodução histórica de modelos de desenvolvimento cuja centralidade da tomada de decisão ocorre em espaços exógenos, excludentes e anteriores da participação social (SCABIN, 2015; ZHOURI, 2014), localizados nos centros econômicos capitalistas nacionais ou internacionais, está à incapacidade do setor público e empresarial em saber lidar com os conhecimentos, as mobilizações e os posicionamentos políticos das populações locais, ora deslegitimando-os com discursos e propagandas que superestimam os (alegados) benefícios e minimizam os efeitos dos malefícios, ora autorizando-as desde que adaptadas a formatos institucionais de participação que reduzem ou impedem o dissenso e a contestação aos interesses hegemônicos, ora criminalizando-os e, até, promovendo ações direta de chantagem, coerção, ameaça, espionagem e/ou assassinato de lideranças e defensores de direitos humanos, objetivando fragilizar a mobilização social e a força de seus argumentos.

Por outro lado, os espaços institucionais de participação social, como a audiência pública do licenciamento ambiental e a consulta aos povos indígenas e comunidades tradicionais, convertem-se em momentos formais - excessivamente burocratizados e, cada vez mais, militarizados - destituídos do poder de deliberação e/ou da capacidade de influenciar os rumos do grande empreendimento, restando às populações locais o caminho da judicialização das demandas e das irregularidades dos empreendimentos - algo também enleado em cenários de politização do Judiciário que retardam ou impedem a obtenção das demandas pleiteadas - ou a realização de ações diretas de protesto e reivindicação, as quais, novamente, são alvo de novas formas de criminalização.

Em tal análise geral, não é difícil constatar a exclusão das crianças e dos adolescentes dos espaços de decisão sobre os grandes empreendimentos por questões procedimentais e culturais. De um lado, tem-se a institucionalização de formas de participação social que adotam metodologias, linguagens e formato de negociação política que pouco estimula a participação de crianças e adolescentes e, quando o fazem, reduzem-na ao mero papel de ouvintes, e não de participantes ativas. Por outro, há uma hegemonia da percepção de crianças e adolescentes como vítimas, e não como protagonistas, das formas de violação e de resistência que se empreende nos cenários de implantação de grandes empreendimentos 
(OLIVEIRA, 2014b; SOARES, 2014), o que acaba por reforçar o papel adultocêntrico dos sujeitos no tratamento dos problemas relativos às crianças e aos adolescentes com a desconsideração de suas opiniões e maneiras próprias de simbolização e de participação.

Num contexto político de constante evocação à capacidade das novas gerações de produzirem novas formas de participação nos e de recriação dos espaços públicos, as ações coletivas infanto-adolescentes-juvenis deflagradas em diferentes contextos sociais tem possibilitado, tal como o movimento do rolezinho analisado por Vommaro (2014), o tensionamento e o desmascaramento das limitações dos próprios espaços públicos, no ato mesmo de ocupa-los, reapropriá-los e reconfigurá-los.

Por isso, o desafio é a adequação linguística, procedimental, cultural e, fundamentalmente, política dos espaços de decisão, de modo a torná-los mais aptos à presença de crianças e adolescentes, seja em termos de garantir sua participação, seja, e o que é mais difícil, de proporcionar uma escuta atenta de seus dizeres que obtenha ressonância nas decisões a serem tomadas sobre os grandes empreendimentos. Logo, participação com protagonismo é o dilema que acompanha as crianças e os adolescentes, assim como à população local em que se inserem.

Certamente, as crianças e os adolescentes se inserem dentro de um segmento mais amplo de "grupos vulneráveis" que possuem formas de afetação e tratamento diferenciados no contexto de implantação e operacionalização de grandes empreendimentos. Trata-se de mulheres, idosos, pessoas com deficiência, povo e comunidades tradicionais, além das crianças e dos adolescentes, que não apenas sofrem as violações decorrentes do processo geral de implantação dos grandes empreendimentos, mas também danos específicos que se articulam aos seus marcadores sociais da diferença, além de reduzir a capacidade de escuta e de participação.

Em todo caso, as proposições construídas nos documentos da REVSCA (Quadro 4) buscam dar um salto de qualidade no papel da sociedade civil e, particularmente, das crianças, dos adolescentes e dos órgãos de controle social relacionados a eles, indicando, com isso, referenciais para fortalecer a incidência política e o protagonismo infanto-adolescente nos espaços de decisão sobre os grandes empreendimentos. 


\section{Quadro 4. Sistematização do Conteúdo}

\begin{tabular}{|c|c|}
\hline Documentos & Conteúdo \\
\hline $\begin{array}{l}\text { Carta de Porto } \\
\text { Velho } \\
\text { (CNEVSCA, 2011) }\end{array}$ & $\begin{array}{l}\text { "Assegurar a participação equitativa da sociedade civil no } \\
\text { processo de deliberação da agenda de infraestrutura nacio- } \\
\text { nal" (p. 3). }\end{array}$ \\
\hline $\begin{array}{l}\text { Exploração Sexual } \\
\text { e Grandes Obras } \\
\text { (CHILDHOOD, } \\
\text { 2011) }\end{array}$ & $\begin{array}{l}\text { "Criar espaços efetivos e equitativos, bem como ferramentas } \\
\text { de participação e controle social, previamente ao licencia- } \\
\text { mento, durante e após a execução da obra" (p. 16). } \\
\text { "Pautar os governos e as empresas do setor privado para o } \\
\text { desenvolvimento de trabalhos preventivos, de modo a mini- } \\
\text { mizar os impactos das grandes obras antes do licenciamento } \\
\text { ambiental. Trata-se aqui do empoderamento da sociedade } \\
\text { civil para que esta possa definitivamente chegar ao Estado, } \\
\text { interferindo de modo efetivo na formulação de políticas pú- } \\
\text { blicas para a proteção da infância e adolescência contra a ex- } \\
\text { ploração sexual de crianças e adolescentes" (p. 17). } \\
\text { "Colaborar tanto com governos quanto com empresas no } \\
\text { sentido de disponibilizar metodologias, tecnologias sociais, } \\
\text { ou seja, alimentar as possibilidades de construção de ações } \\
\text { preventivas nos municípios, a partir da tecnologia social de- } \\
\text { senvolvida por entidades da sociedade civil" (Idem). } \\
\text { "Acionar o Ministério Público para disponibilizar informa- } \\
\text { ções sobre os empreendimentos" (Idem). } \\
\text { "Assegurar transparência nos atos da execução das compen- } \\
\text { sações sociais, por meio de audiências públicas e sistemas de } \\
\text { monitoramento e acompanhamento" (Idem). } \\
\text { "Monitorar as propagandas que enfatizem apenas os impac- } \\
\text { tos positivos das obras (Idem). }\end{array}$ \\
\hline $\begin{array}{l}\text { Carta } 18 \text { de maio } \\
\text { (CNEVSCA, 2012) }\end{array}$ & $\begin{array}{l}\text { "Reafirmamos que a necessidade de que as instâncias da } \\
\text { política de direitos humanos criem processos e mecanis- } \\
\text { mos sistemáticos, plurais e periódicos de monitoramento } \\
\text { das ações de desenvolvimento econômico em conformidade } \\
\text { com a recomendação do Comitê das Nações Unidas para os } \\
\text { Direitos da Criança" (p. 2). } \\
\text { "Ressaltamos a importância do Conselho Nacional dos Direi- } \\
\text { tos da Criança e do Adolescente liderar processos de debate } \\
\text { público e monitoramento da relação entre opções econômi- } \\
\text { cas e direitos humanos da criança" (Idem). }\end{array}$ \\
\hline
\end{tabular}


Pacto CONANDA

(CONANDA, 2012)
"Criar e fortalecer a Comissão de Enfrentamento a Violência Sexual de crianças e adolescentes, [com] participação de órgãos, instituições como representante do poder executivo, polícia civil, polícia militar, garantindo a interlocução sobre o tema com a CCBM - Consórcio Construtor Belo Monte, em especial a assinatura e efetivação do pacto de compromisso" (p. 2).

"Garantir o protagonismo de crianças e adolescentes em consonância com o eixo 3 do plano decenal e em especial nos conselhos de direitos e na gestão escolar" (Idem).

"CONANDA, CEDCA e CMDCA encaminhar ofício ao TCU, TCE, TCM solicitando auditorias de recursos e funcionais nos municípios onde estão ocorrendo grandes obras e ao Ministério Público Federal e Estadual a fiscalização dos recursos que estão sendo disponibilizados criando uma agenda permanente de monitoramento e realização de audiências públicas" (p. 4).

"Fortalecer a incidência de monitoramento na política da infância e adolescência” (Idem).

"Estabelecer mecanismos adequados de mobilização social para participação em audiências públicas deliberativas anteriores a aprovação da instalação das obras, garantindo representação de todos os setores da sociedade, com ênfase para o envolvimento de crianças e adolescentes impactadas pelo projeto, e o não cumprimento das deliberações da audiência pública deve ser objeto de ação civil pública" (Idem).

"Garantir a participação das comissões e conselhos setoriais criando mecanismos para que os Conselhos de Direitos municipais façam parte dos comitês de acompanhamento local dos empreendimentos Belo Monte" (Idem).

"Obrigar que as empresas encaminhem os planos, programas e projetos voltados para o atendimento das crianças e dos adolescentes" (Idem).

"Garantir a participação de povos e comunidades tradicionais, em especial indígenas, ribeirinhos e quilombolas, nos Conselhos de Direito, nos Conselhos da Educação e da Merenda Escolar, nas três esferas existentes, proporcionando condições específicas para a seleção dos representantes, respeitando a autonomia, os direitos e as especificidades culturais" (p. 5). 


\begin{tabular}{|l|l|}
\hline $\begin{array}{c}\text { Carta de Altamira } \\
\text { (CNEVSCA, 2013) }\end{array}$ & $\begin{array}{l}\text { "Fortalecimento dos grupos infanto-adolescentes para par- } \\
\text { ticipação em todos os estágios e espaços de negociação das } \\
\text { grandes obras de infraestruturas e de apropriação dos re- } \\
\text { cursos naturais, em especial nos Conselhos, Fóruns e Comi- } \\
\text { tês formados para administração de ações e recursos rela- } \\
\text { cionados com estas grandes obras, adotando e respeitando o } \\
\text { princípio do melhor interesse da criança" (p. 2). } \\
\text { "Modificação do modelo de audiências públicas destinado às } \\
\text { populações locais tornando-o de caráter deliberativo e que } \\
\text { utilize metodologia adequada para a participação social e o } \\
\text { diálogo entre os sujeitos interessados, além da obrigatória } \\
\text { promoção de audiências públicas nos espaços de protago- } \\
\text { nismo infanto-adolescente, como a escola, os centros de re- } \\
\text { creação, entre outros locais" (p. 3). } \\
\text { "Criação de uma Comissão Nacional composta por represen- } \\
\text { tantes das populações afetadas, dos trabalhadores das obras } \\
\text { e instâncias governamentais responsáveis, com a prerroga- } \\
\text { tiva de avaliar os efeitos socioambientais e revisar os pro- } \\
\text { cessos de licenciamento e implementação das políticas com- } \\
\text { pensatórias" (p. 5). }\end{array}$ \\
\hline
\end{tabular}

Os valores predominantes nas proposições são os da democratização e da politização dos espaços de deliberação sobre os grandes empreendimentos, com três matizes distintos. Em primeiro, demanda-se a inserção da sociedade civil como participante ativa na totalidade dos espaços de decisão que conformam o planejamento e a execução dos grandes empreendimentos, desde antes de seu ingresso no licenciamento ambiental, até após a operacionalização do empreendimento, galgando um redesenho político-institucional dos espaços e procedimentos existentes, tornando-os mais favoráveis à participação e mais acolhedores do posicionamento de sujeitos e grupos.

Nessa perspectiva, o papel da sociedade civil não se restringe a de identificadora de formas de afetação dos grandes empreendimentos às condições de vida de crianças e adolescentes, mas também a de coparticipes da gestão das soluções a serem buscadas, inclusive na disponibilização de expertise para facilitação da consulta às crianças e aos adolescentes (INTERNATIONAL COMISSION OF JURISTS, 2015) e na construção de ações preventivas.

Um segundo aspecto é o empoderamento dos órgãos de controle social, com ênfase no Conselho de Direitos da Criança e do Adolescente 
(CDCA), em suas três esferas (federal, estadual e municipal), para que seus atos e competências de monitoramento tenham influência direta nos espaços de decisão e no arranjo de execução dos grandes empreendimentos. Com isso, o monitoramento ganha contornos de instrumento gerencial e avaliativo (RODRIGUES, 2011; VEIGA, 2015) de democratização da gestão política dos grandes empreendimentos, focalizado nos seus processos e resultados, tendo por referencia (de cobrança e de legitimação) a garantia dos direitos às crianças e aos adolescentes.

Isto encontra respaldo no Comentário Geral no․ 16/2013 do Comitê dos Direitos da Criança da ONU, que adverte, em seu item 61, alínea "a"19, para a necessidade de fortalecimento dos organismos de supervisão das normas relativas aos direitos das crianças, listando uma série de temáticas que tem por direcionamento, no Brasil pós-CF/88, os conselhos setoriais, com ênfase ao CDCA, assim como ao Ministério Público. Logo, a perspectiva adotada alarga o dever e o direito do controle social de influir com suas decisões nos espaços institucionais dos grandes empreendimentos, demandando, para tanto, que o controle social assuma a pauta de problematização e incidência nos grandes empreendimentos como umas das prioritárias de atendimento na condução de suas atividades.

Por terceiro, está o investimento na participação e protagonismo das crianças e dos adolescentes. Percebe-se que muitas proposições têm o cuidado de exigir uma dupla participação e protagonismo das crianças e dos adolescentes: nos espaços de decisão dos grandes empreendimentos, sobretudo a audiência pública do licenciamento ambiental; nos demais espaços da rede de proteção, especialmente os conselhos setoriais.

Há de se discutir, porém, de que modo se daria a construção metodológica dessa participação, para que não se reduzisse apenas a mero objetivo quantitativo. Para tanto, e de início, há de se reconhecer a participação de crianças e adolescentes como direito estabelecido no artigo $12^{20}$ da Convenção dos Direitos da Criança e no artigo 16, inciso II ${ }^{21}$, do ECA, que reforça o cumprimento da medida como obrigação jurídica passível de acionamento judicial, e não discricionariedade dos agentes estatais, sociais ou empresariais.

Por outro lado, há de se redobrar o cuidado com os caminhos que a ênfase no protagonismo infanto-adolescente pode assumir, inclusive de 
revitalização das formas de dominação dos sujeitos. É salutar a advertência de Souza (2009) quanto aos riscos de se assumir "soluções" calcadas no fomento à participação individualizada como recurso tautológico de legitimação de consensos pré-estabelecidos e de homogeneização do social. Isto afeta, fundamentalmente, a dimensão da política, no sentido de transgressão às condições estabelecidas - ou seja, de não redução das alternativas participativas apenas ao "consenso participativo" -, o reconhecimento das desigualdades de poder entre os diferentes sujeitos/ grupos, assim como a imprevisibilidade dos resultados advindos do exercício do direito à participação, os quais podem extrapolar até mesmo os limites das alternativas traçadas de fazer política nos espaços de decisão dos grandes empreendimentos.

Assim, garantir o direito à participação de crianças e adolescentes é necessariamente repensar as formas de participação instituídas desde as especificidades geracionais, em atenção às suas condições de sujeitos de direitos em condição peculiar de desenvolvimento, portanto, em respeito ao paradigma da proteção integral vigente no Brasil a partir da CF/88.

Trata-se de desconstruir o adultocentrismo inerente (e, por isso, naturalizado) às dinâmicas de interação e tomada de decisão presente nos espaços de participação social e nos espaços de deliberação estatal-empresarial sobre os grandes empreendimentos, reconhecendo a necessidade de não discriminar negativamente a capacidade interventiva e a opinião de crianças e adolescentes ${ }^{22}$ sobre os grandes empreendimentos, os impactos nos seus direitos humanos e as proposições de medidas preventivas e resolutivas aos problemas evidenciados, promovendo a inserção dos agentes estatais e empresariais diretamente implicados nesses empreendimentos nos espaços com maior facilidade de mobilização do público infanto-adolescente, além de discutir a remodelagem da metodologia de deliberação para torná-la mais adequada às dinâmicas de interação e linguagem desse segmento, em suas diferentes etapas de desenvolvimento e formações socioculturais. 


\section{CONSIDERAÇÕES FINAIS}

O conteúdo dos documentos políticos analisados constitui-se em fonte de expansão das fronteiras dos direitos humanos e recursos interpretativos para a adequação das políticas de desenvolvimento e práticas empresariais via força hermenêutico-normativa dos direitos das crianças e dos adolescentes.

Fundamentalmente, são proposições que apontam para outra forma de lidar com os direitos das crianças e adolescentes a partir do olhar estratégico sobre o planejamento territorial, pensando-o como momento chave para o investimento de recursos públicos que assegurem o cumprimento dos direitos já normatizados, assim fortalecendo a perspectiva da prevenção e do acesso aos bens e serviços independente da implantação de grandes empreendimentos, mas pelo simples fato de crianças e adolescentes serem sujeitos de direitos.

Em paralelo, as proposições evidenciam a disputa pela concepção de desenvolvimento plasmada no critério-matriz da garantia de direitos à população local, e às crianças e aos adolescentes nela inseridos, em que o desenvolvimento se torna um meio para o desfrute desses direitos, ao mesmo tempo em que é instrumentalizado para melhor desenvolver seus aspectos práticos e procedimentais.

De forma similar, encontra-se a situação do licenciamento ambiental. 0 alinhamento ao paradigma constitucional da proteção integral e, de maneira mais específica, ao princípio da prioridade absoluta - e ao princípio do melhor interesse da criança -, reposiciona as crianças e os adolescentes para o devido patamar de importância na totalidade dos elementos que compõe o licenciamento, indicando a plena possibilidade de promover mudanças que estabeleçam condições mais seguras de identificação, prevenção e/ou minimização de impactos às crianças e aos adolescentes, assim como potencialização de aspectos positivos relacionados aos empreendimentos.

Isto revela, por outro lado, o quanto é preciso avançar num melhor equilíbrio da relação (e da valoração) entre os danos ambientais e os danos sociais, ainda que neste último a caracterização dos atingidos ou afetados deve ser depurada a partir de diferentes (e complexos) ele- 
mentos identitários e sociais que definem formas específicas de afetação aos diferentes grupos que compõe determinado território, as quais não podem ser reduzidas em inscrições homogêneas ou totalizadas de atingidos ou afetados, ante o imperativo da diversidade das expressões dos sujeitos, incluindo as crianças e os adolescentes, mas não somente eles.

Em sendo assim, cabe também às empresas cada vez mais atentarem para a incidência de tais danos e dos direitos dos sujeitos que os sofrem, para não apenas apoiar as instituições e entidades locais no fortalecimento de suas ações, mas, efetivamente, reconhecendo-se como parte dessa rede de proteção. As proposições analisadas buscam ressaltar o novo papel que a sociedade espera das empresas, colocando-se como ativa promotora dos direitos das crianças e dos adolescentes, o que, muitas vezes, só será possível mediante a realização de ajustes na dinâmica empresarial.

Mas tudo isso não teria sentido sem a presença e a participação constante da sociedade e, particularmente, do protagonismo de crianças e adolescentes nos espaços de decisão dos grandes empreendimentos, invertendo a lógica histórica de planejamento e implantação pela ótica da democratização das decisões que vão embasar o planejamento, a execução e o monitoramento dos empreendimentos.

É por isso que a participação social e o protagonismo infanto-adolescente são proposições transversais às outras, não apenas constituem-se em direitos a serem assegurados, mas, com essa efetivação, redefinem a lógica de conformação das outras linhas estruturais de proposições, pois as condicionam à capacidade dos agentes locais de incidirem nos espaços de decisão, fazendo-os operar desde os arranjos delineados no âmbito local e, com isso, ampliando as chances de harmonização entre direitos das crianças, políticas de desenvolvimento e práticas empresariais.

Por fim, seria importante a ampliação do leque de articulação por meio de intercâmbios e parcerias com países da América Latina e de outros continentes, como África e Ásia, que passam por processos semelhantes de adensamento de grandes empreendimentos pela lógica do neodesenvolvimentismo. 


\section{NOTAS}

1 Para tanto, segundo Jiménez Benítez (2007) faz-se necessário diferenciar os direitos humanos entendidos como "resultado-fim" de obtenção de bem jurídico reconhecido, do "enfoque de direitos humanos", entendido como processo-meio, como "forma de ver" e "maneira de fazer" para lograr a concretização desses direitos, ou seja, como ferramentas para a reconstrução das políticas e ações socioestatais.

2 O denominado neodesenvolvimentismo brasileiro e latino-americano consiste num conjunto de estratégias de desenvolvimento pautadas no aproveitamento do crescimento do preço global de diversas commodities sustentado pela intensificação da demanda de países asiáticos, europeus e da América do Norte, com especial ênfase à China, Índia e Estados Unidos (ALMEIDA, 2012, MESQUITA, 2011, VERDUM, 2007). Com isso, os governos latino-americanos têm investido na reprimarização das exportações para o comércio exterior mediante a adoção de políticas de desenvolvimento pautadas na melhoria da infraestrutura de escoamento e suprimento de demandas básicas (água, energia, minérios, etc.), assim priorizando o fortalecimento de setores econômicos ligados ao agronegócio e ao minério, ambos impulsionados pela execução de grandes empreendimentos que têm na Amazônia um dos principais focos de expansão da fronteira capitalista. Nos últimos anos, no entanto, a queda generalizada do preço de várias commodities no mercado global tem provocado dificuldade de manutenção da priorização do neodesenvolvimentismo, apesar de isto não ter surtido efeitos consideráveis, ainda, no planejamento dos grandes empreendimentos do PAC.

3 O SGD, também conhecido por rede de proteção ou política de atendimento às crianças e aos adolescentes, constitui-se, segundo a Resolução no. 113/2006 do CONANDA, "na articulação e integração das instâncias públicas governamentais e da sociedade civil, na aplicação de instrumentos normativos e no funcionamento dos mecanismos de promoção, defesa e controle para a efetivação dos direitos humanos da criança e do adolescente, nos níveis Federal, Estadual, Distrital e Municipal" (2006, p.1). Nesse sentido, conforme dispõe Martins, forjou-se numa nova concepção de atendimento, albergada pela Doutrina da Proteção Integral, "voltada não apenas para as 'irregularidades', mas principalmente para medidas de caráter geral e preventivas, destinadas a toda e qualquer criança e adolescente, sendo seu paradigma a erradicação das violações de direitos de crianças e adolescentes através da proteção integral dos interesses dos mesmos" (2009, p. 52).

4 O III Congresso Mundial trouxe o tema da "responsabilização social corporativa" como um dos eixos de discussão sobre o enfrentamento da exploração sexual de crianças e adolescentes, incluindo, na programação oficial, o Painel 4 "Iniciativas de Responsabilidade Social". Na "Declaração do Rio e Chamada para Ação para Prevenir e Eliminar a Exploração Sexual de Crianças e Adolescentes", elaborada durante o evento, consta um item específico de "responsabilidade social corporativa" que possuía a proposição, às empresas, de "Integrar a proteção da criança, inclusive a prevenção da exploração sexual de crianças, a políticas novas ou já existentes de responsabilidade social corporativa de empresas que operam, entre outros, nos serviços de turismo, viagens, transporte, agricultura e finanças, e nos setores de comunicação, mídia, provedores de Internet, propaganda e entretenimento, e garantir a implementação apropriada de tais políticas e da difusão da consciência pública" (BISPO; PAIVA, 2010, p. 81). Sem dúvida, o modo como o tema da implicação das práticas empresariais nos direitos sexuais de crianças e adolescentes foi tratado no evento repercutiu numa maior atenção pública para os locais de atuação de consórcios empresariais na execução de grandes empreendimentos, em que os cenários traçados no evento ganhavam escalas maiores de impactos e, portanto, de responsabilização empresarial e de atuação do Estado.

5 Atenção dada, sobretudo, por serem as maiores hidrelétricas de um conjunto de dezenas de outras hidrelétricas projetadas ou em construção no Brasil, com foco maior na Amazônia. Segundo Bermann (2012), o Plano Decenal de Energia (2011-2020) e o Plano Nacional de Energia prevêem a implantação de 30 hidrelétricas até 2020 na área correspondente a Amazônia legal, num total de 48 a serem instaladas em todo o Brasil, como partes do PAC. No período mais recente, Fearnside comenta que: "[a] retração econômica do Brasil, desde esse plano, resultou no alongamento dos horizontes temporais para vários desses projetos, mas o plano de 2014-2023 ainda inclui 18 repre- 
sas amazônicas na sua lista para construção em 10 anos... Muitas outras têm sido inventariadas..., incluindo 62 barragens adicionais listadas no 'Plano 2010’” (2015, p. 262).

60 paradigma da proteção integral, também conhecido por Doutrina da Proteção Integral, foi estabelecido, no Brasil, a partir da Constituição Federal de 1988, "que incorporou ao ordenamento jurídico brasileiro a Teoria da Proteção Integral, no seu artigo 227, com o reconhecimento a uma série de direitos fundamentais, como o direito à vida, à saúde, à alimentação, à educação, ao lazer, à profissionalização, à cultura, à dignidade, ao respeito e à liberdade, bem como, o direito à convivência familiar e comunitária. No momento em que os estabeleceu, elencou a família, a sociedade e o Estado como os responsáveis pelo cumprimento de tais garantias fundamentais" (CABRAL, 2012, p. 69). Sobre o assunto, também consultar: Amin (2010), Oliveira (2014a), Richter, Vieira e Terra (2010), Rossato, Lépore e Sanches (2013) e Veronese (2015).

7 Retroalimenta-se, assim, o legado ético-normativo da Declaração sobre o Direito ao Desenvolvimento da ONU, de 1986, que estabelece, em seu artigo $1^{\circ}$, inciso 1, “[o] direito ao desenvolvimento é um direito humano inalienável, em virtude do qual toda pessoa e todos os povos estão habilitados a participar do desenvolvimento econômico, social, cultural e político, para ele contribuir e dele desfrutar, no qual todos os direitos humanos e liberdades fundamentais possam ser plenamente realizados" (ONU, 1986).

8 Concorda-se com o posicionamento de Bermann a respeito da inadequação conceitual do uso do termo "impacto" para caracterizar "os processos sociais e territoriais de implantação de usinas hidrelétricas... a palavra impacto tornou-se meramente administrativa, prescrita para ser utilizada nos processos de licenciamento ambiental, mas contraproducentes em termos científicos e impeditiva para o avanço do conhecimento, tornando-se tão somente uma noção desviacionista" (2014, p. 96). Nesse caso, o autor indica ser mais correto usar termos "perdas, prejuízos, danos, desastres, expulsões, expropriações, desaparecimentos, privações, ruínas, desgraças, destruições de vidas e bens, muitas vezes permanentes e irreversíveis" (2014, p. 97. Grifos do autor).

9 O “paradigma da adequação ambiental” (ZHOURI, 2013) constitui-se no processo de flexibilização do licenciamento ambiental para que ele assuma ações mitigadoras, sem que isto traga obstáculos à execução das grandes obras. Nesse sentido, Zhouri comenta que, nele, o licenciamento ambiental está destinado a viabilizar o projeto técnico, incorporando-lhe algumas "externalidades" ambientais e sociais na forma de medidas mitigadoras e compensatórias, desde que estas, obviamente, não inviabilizem o projeto do ponto de vista econômico-orçamentário. Dessa forma, assegura-se a dominação do espaço de tomada de decisões por uma visão hegemônica do que sejam as possibilidades de "uso" dos recursos naturais a partir da lógica de mercado" (2013, p. 49-50).

10 Os quais, segundo Bermann (2012) e Garzon (2014), constroem um circuito específico de mutua colaboração, pois são as empresas privadas que conseguem os contratos multimilionários das licitações para construir as grandes obras, as que, paradoxalmente, mais investem financeiramente em doações nos períodos de campanha para todos os partidos políticos - seja os que estão na situação ou na oposição. Daí a importância, no Brasil e em países latino-americanos, de discutir uma reforma política que defina a exclusividade do financiamento público das campanhas eleitorais dos partidos políticos, evitando, com isso, práticas de clientelismo e de corrupção que vão desaguar, em última instância, no acirramento do fomento às grandes obras e aos empréstimos públicos bilionários às empresas ou consórcios empresariais que ganham as licitações.

11 Segundo Oliveira as lacunas das condicionantes são "reflexo de um Estudo de Impacto Ambiental (EIA) e de políticas compensatórias/mitigatórias que não desenvolveram qualquer interlocução com o quadro das demandas históricas referentes ao enfrentamento da violência social [e de outras demandas] na região, e que tinham por 'fontes de reivindicação' os órgãos de controle social, especialmente os conselhos setoriais municipais, sendo que os movimentos sociais jamais foram consultados ou tiveram suas demandas incorporadas como medidas plausíveis de identificação de impactos e de políticas compensatórias ou mitigatórias" (2015, p. 143-144).

12 "Art. 4ํ́ É dever da família, da comunidade, da sociedade em geral e do poder público assegurar, com absoluta prioridade, a efetivação dos direitos referentes à vida, à saúde, à alimentação, à educação, ao esporte, ao lazer, à profissionalização, à cultura, à dignidade, ao respeito, à liberdade e à convivência familiar e comunitária. Parágrafo único. A garantia de prioridade compreende: a) primazia de receber proteção e socorro em quaisquer circunstâncias; b) precedência de 
atendimento nos serviços públicos ou de relevância pública; c) preferência na formulação e na execução das políticas sociais públicas; d) destinação privilegiada de recursos públicos nas áreas relacionadas com a proteção à infância e à juventude" (BRASIL, 1990).

13 Ainda que a intersetorialidade também esteja presente no campo do direito e da política ambiental no Brasil, como bem ressalta Santilli: "[a] questão ambiental não é tratada apenas no capítulo da Constituição especificamente destinado ao meio ambiente, mas está presente em diversos outros capítulos do texto constitucional (econômica, desenvolvimento agrário, etc.), consagrando a orientação de que as políticas públicas ambientais devem ser transversais, ou seja, perpassar o conjunto das políticas públicas capazes de influenciar o campo socioambiental" (2005, p. 65). Em sendo assim, tratar-se-ia de alargar este horizonte de transversalidade no campo ambiental com a inclusão das políticas públicas da rede de proteção aos direitos das crianças e dos adolescentes, as quais, não é demais lembrar, também envolve, em sua maioria, a atenção a outros grupos pouco tratados na seara ambiental, como idosos, mulheres, pessoas com deficiência e jovens, delineando uma projeção de ampliação ainda maior do horizonte da transversalidade no campo ambiental.

14 Ainda que, como observam Martin-Ortega e Wallace (2013) e Oliveira (2014c), a dimensão do paradigma da proteção integral já tenha em si a consideração o reconhecimento das várias dimensões dos direitos humanos a que são destinatárias as crianças e aos adolescentes, "[i]n particular with regards to children's rights, it follows the increased recognition of children as socio-economic rights bearers, independently of the society or family unit of which they form part" (MARTIN-ORTEGA, WALLACE, 2013, p. 3).

15 Conforme ressaltam Pasin e Borges: "[a]vançando nessa recuperação do histórico nacional de parceria entre os setores público e privado, a legislação mais recente sobre concessões, de meados da década de 90, definiu, de forma mais clara que a legislação anterior, a transferência de atividades do Estado para entes privados. Nesse sentido, é provável que quase toda PPP venha a ocorrer no âmbito das concessões. 0 modelo de formação de sociedades privadas de propósito específico, como as concessionárias de serviços públicos, que podem acessar os mercados financeiro e de capitais, permitiu avanços após o esgotamento da capacidade de investimento e de endividamento do setor público. O BNDES vem tendo uma participação expressiva na provisão de fontes e mesmo na estruturação dessas operações" (2003, p. 180).

16 Conforme estabelecido no artigo 13 do POEDH: "[a] responsabilidade de respeitar os direitos humanos exige que as empresas: A. Evitem que suas próprias atividades gerem impactos negativos sobre direitos humanos ou para estes contribuam, bem como enfrentem essas consequências quando vierem a ocorrer; B. Busquem prevenir ou mitigar os impactos negativos sobre os direitos humanos diretamente relacionadas com operações, produtos ou serviços prestados por suas relações comerciais, inclusive quando não tenham contribuído para gerá-los" (CONECTAS, 2012, p. 11).

17 "Since children are still in the developmental phase in terms of their physical, emotional and mental growth, they can be particularly vulnerable to negative business impacts com be disproportionately, severely and permanently affected by violations of their rights" (International Comission of Jurists, 2015, p. 6).

18 "A partir de 2003, uma nova composição de interesses se processou mediante: a) reformas regulatórias; b) suporte operacional dado pelas estatais remanescentes ao setor privado; c) direcionamento do financiamento público a determinados setores via BNDES. O BNDES referenda estratégias de conglomeração empresarial nos setores "comprovadamente competitivos", constituindo-se em um dos principais centros articuladores e de combinação de processos de centralização e concentração de capital no Brasil e no subcontinente. Dessa forma, os pactos político-empresariais, em constante constituição e reconstituição, acabam espelhando o que vem sendo denominado projeto de país e de região. O Programa de Aceleração do Crescimento (PAC), especialmente em sua fase II (2011- 2014), procura se adequar ao cenário pós-crise, contando com maciço apoio do BNDES. O Banco tem servido de atalho para entendimentos político-econômicos objetivos, expressados nas principais fusões e aquisições verificadas nos últimos anos, que contaram invariavelmente com sua condução. Como lugar prioritário para a síntese da relação Estado-capital concentrado no Brasil, o BNDES está gerando novas formas de integração e articulação entre o setor privado e o setor público" (GARZON, 2014, p. 26). 
19 “61. Generalmente, la falta de aplicación o el cumplimiento deficiente de las leyes que regulan las empresas plantean los problemas más críticos para los niños. Hay una serie de medidas que los Estados deben adoptar para garantizar la aplicación y el cumplimiento efectivos, entre otras: a) Fortalecer los organismos reguladores responsables de la supervisión de las normas relativas a los derechos del niño, como la salud y la seguridad, los derechos del consumidor, la educación, el medio ambiente, el trabajo, y la publicidad y la mercadotecnia, de modo que cuenten con las competencias y los recursos suficientes para vigilar e investigar las denuncias y establecer y hacer aplicar recursos contra las violaciones de los derechos del niño" (ONU, 2013, p. 17-18).

20 "Artigo 12 - 1. Os Estados Partes assegurarão à criança que estiver capacitada a formular seus próprios juízos o direito de expressar suas opiniões livremente sobre todos os assuntos relacionados com a criança, levando-se devidamente em consideração essas opiniões, em função da idade e maturidade da criança. 2. Com tal propósito, se proporcionará à criança, em particular, a oportunidade de ser ouvida em todo processo judicial ou administrativo que afete a mesma, quer diretamente quer por intermédio de um representante ou órgão apropriado, em conformidade com as regras processuais da legislação nacional" (ONU, 1990).

21 "Art. 16. 0 direito à liberdade compreende os seguintes aspectos:... II - opinião e expressão" (BRASIL, 1990).

22 Em estreita conexão com o disposto na Declaração e no Programa de Ação da Conferência de Direitos Humanos de Viena, de 1993, que estabeleceu que "no tocante a todas as iniciativas relativas às crianças, a não discriminação e o melhor interesse para a criança deverão constituir-se considerações prioritárias, devendo-se igualmente ter em consideração as opiniões expressas pelas crianças" (ONU, 1993).

\title{
REFERÊNCIAS
}

\begin{abstract}
ABRAMOVICH, Víctor. Una Aproximación al Enfoque de Derechos en las Estrategias y Políticas de Desarrollo de América Latina. Santiago: CELS, 2004.
\end{abstract}

ALMEIDA, Alfredo Wagner Berno. Territórios e territorialidade específicas na Amazônia: entre a "proteção" e o "protecionismo". Cadernos CRH, 25 (64), p. 63-71, 2012. Disponível em: http://www.scielo.br/pdf/ccrh/v25n64/05.pdf

AMIN, Andréa Rodrigues. Doutrina da Proteção Integral. In: MACIEL, Kátia Regina F. L. A. (coord.). Curso de Direito da Criança e do Adolescente: aspectos teóricos e práticos. 4 ed. Rio de Janeiro: Lumen Juris, p.19-30, 2010.

BERMANN, Célio. 0 projeto da Usina Hidrelétrica de Belo Monte: a autocracia energética como paradigma. Novos Cadernos NAEA, 15 (1), p. 5-23, 2012.

. A desconstrução do licenciamento ambiental e a invisibilização do social nos projetos de usinas hidrelétricas. In ZHOURI, Andrea; VALENCIO, Norma (orgs.). Formas de matar, de morrer e de resistir: limites da resolução negociada de conflitos ambientais. Belo Horizonte: UFMG, p. 94-109, 2014. 
BISPO, Eliane; PAIVA, Leila (orgs.). Anais do III Congresso Mundial de Enfrentamento da Exploração Sexual de Crianças e Adolescentes. Brasília: Centro de Referência, Estudos e Ações sobre Crianças e Adolescentes - CECRIA, 2010.

BRASIL. Lei № 8.069, de 13 de julho de 1990 (Estatuto da Criança e do Adolescente). Brasília: Casa Civil, 1990. Disponível em: http://www.planalto. gov.br/ccivil_03/leis/ L8069.htm

CABRAL, Johana. Família, sociedade e Estado na promoção e defesa dos direitos humanos da criança e do adolescente: um estudo da Teoria da Proteção Integral. Criciúma: UNESC, 2012.

CASTRO, Edna. Políticas de estado e atores sociais na Amazônia contemporânea. In: BOLLE, Willi; CASTRO, Edna; VEJMELKA, Marcel (orgs.). Amazônia: região universal e teatro do mundo. São Paulo: Globo, p. 105-122, 2010.

CENTRO DE SUSTENTABILIDADE GV (GVCES). Geração de Valor Compartilhado a partir da Proteção Integral de Crianças e Adolescentes: uma proposta de diretrizes empresariais no contexto de grandes empreendimentos. São Paulo: GVces/FGV, 2013.

CHILDHOOD. Exploração Sexual e Grandes Obras: construção de uma agenda de convergência para o enfrentamento da exploração sexual de crianças e adolescentes. São Paulo: Childhood, 2011.

COMITÊ NACIONAL DE ENFRENTAMENTO DA VIOLÊNCIA SEXUAL CONTRA CRIANÇAS E ADOLESCENTES (CNEVSCA). Carta de Porto Velho. Porto Velho: CNEVSCA, 2011. Disponível em: www.pair.ledes.net

. Carta 18 de maio. Porto Velho: CNEVSCA, 2012. Disponível em: www. pair.ledes.net

Carta de Altamira. Altamira: CNEVSCA, 2013. Disponível em: www.pair. ledes.net

Proposições do Seminário Violência Sexual e Grandes Obras: avanços, dilemas e desafios para a garantia dos direitos de crianças e adolescentes. Altamira: CNEVSCA, 2014. 
CONECTAS. Empresas e Direitos Humanos: parâmetros da ONU para proteger, respeitar e reparar. Relatório final de John Ruggie - Representante Especial do Secretário-Geral. São Paulo: Conectas, 2012. Disponível em: www.conectas.org

CONSELHO NACIONAL DOS DIREITOS DA CRIANÇA E DO ADOLESCENTE (CONANDA). Resolução no. 113, de 12 de abril de 2006. Brasília: CONANDA, 2006. Disponível em: http://www.sdh.gov.br/sobre/participacao-social/ conselho-nacional-dos-direitos-da-crianca-e-do-adolescente-conanda/resolucoes/resolucoes-1

Pacto do CONANDA. Altamira: CMDCA, 2012. Disponível em: www.pair. ledes.net

DRAIBE, Sonia Miriam. Intersetorialidade. In: GIOVANNI, Geraldo Di; NOGUEIRA, Marco Aurélio (orgs). Dicionário de políticas públicas. 2 ed. São Paulo: Editora da Unesp; Fundap, p. 488-492, 2015.

FEARNSIDE, Philip M. Impactos ambientais e sociais de barragens hidrelétricas na Amazônia brasileira: As implicações para a indústria de alumínio. In: FEARNSIDE, Philip M. (ed.) Hidrelétricas na Amazônia: Impactos Ambientais e Sociais na Tomada de Decisões sobre Grandes Obras. Vol. 2. Manaus: Editora do INPA, p. 261-288, 2015.

FRANCO, Heliana Brito; LEAL, Maria de Fátima Mendes. Crianças da Amazônia: um futuro ameaçado. Belém: UFPA; UNAMAZ; UNICEF, 1990.

GARZON, Luís Fernando Novoa. Grandes projetos do PAC: fato consumado ou futuro leiloado? In: PINHO, Vilma Aparecido de; OLIVEIRA, Assis da Costa (orgs.). Direitos Infanto-Juvenis e Violência Sexual em Contexto de Grandes Obras: perspectivas e desafios. Belém: GTR, p. 21-33, 2014.

GERBER, Paula; KYRIAKAKIS, Joanna; O'BYRNE, Katie. General Comment 16 on State Obligation Regarding the Impacts of the Business Sector on Children's Rights: what is it standing, meaning and effect? Melbourne Jornal of International Law, 14, 98-128, 2013.

GRUPO DE DIREITOS HUMANOS E EMPRESAS DA DIREITO (GDHEE). 0 direito à proteção integral das crianças e dos adolescentes no contexto de grandes empreendimentos: papéis e responsabilidades das empresas. 2013. Disponível 
em: http://direitosp.fgv.br/sites/direitosp.fgv.br/files/arquivos/anexos/direitogv_final_04dez2013.pdf

INTERNATIONAL COMISSION OF JURISTS. State Obligations Regarding the Impact of the Business Sector on Children's Rights. Genebra: ICJ; CRIN; OAK Foundation, 2015.

JIMÉNEZ BENÍTEZ, William Guillermo. El Enfoque de los Derechos Humanos y las Políticas Públicas. Civilizar. Ciencias Sociales y Humanas, Bogotá, 7 (12), 31-46, 2007.

KLIKSBERG, Bernardo. 0 papel da responsabilidade social empresarial na crise. In: SEN, Amartya; KLIKSBERG, Bernardo (orgs.). As pessoas em primeiro lugar: a ética do desenvolvimento e os problemas do mundo globalizado. São Paulo: Companhia das Letras, p. 354-375, 2010.

MARIN, Rosa Elisabeth Acevedo; OLIVEIRA, Assis da Costa. Violence and public health in the Altamira region: the construction of the Belo Monte hydroelectric plant. Region and Cohesion, 6 (3), p. 116-134, 2016. DOI: 10.3167/ reco.2015.060106

MARTIN-ORTEGA, Olga; WALLACE, Rebecca. Business, Human Rights and Children: the developing international agenda, The Denning Law Journal, 25, p.105-127, 2013.

MARTINS, Daniele Comin. Estatuto da Criança e do Adolescente \& Política de Atendimento. Curitiba: Juruá, 2009.

MESQUITA, Benjamin Alvino. A dinâmica recente do crescimento do agronegócio na Amazônia e a disputa por territórios. In: SAUER, Sérgio; ALMEIDA, Wellington (orgs.). Terras e territórios na Amazônia: demandas, desafios e perspectivas. Brasília: Editora Universidade de Brasília, p. 45-68, 2011.

NWAUCHE, E. S.; NWOBIKE, J. C. Implementación del derecho al desarrollo. SUR - Revista Internacional de Derechos Humanos, v. 2, n. 17, p. 98-119, 2005.

OLIVEIRA, Assis da Costa. Consequências do neodesenvolvimentismo brasileiro para as políticas públicas de crianças e adolescentes: reflexões sobre a implantação da Usina Hidrelétrica de Belo Monte. Revista de Políticas Públicas, São Luís, 17 (2), p. 289-302, 2013. 
. Indígenas crianças, crianças indígenas: perspectivas para a construção da Doutrina da Proteção Plural. Curitiba: Juruá, 2014a.

. Notas para a formulação de uma política de garantia de direitos sexuais às crianças e aos adolescentes no cenário das grandes obras. In: PINHO, Vilma Aparecida; OLIVEIRA, Assis da Costa (orgs.). Direitos Infanto-Juvenis e Violência Sexual em Contexto de Grandes Obras: perspectivas e desafios. Belém: GTR, p. 49-62, 2014b.

. Princípio da pessoa em desenvolvimento: fundamentos, aplicações e tradução intercultural. Revista Direito e Práxis, 5 (9), p. 60-83, 2014c. DOI 10.12957/dep.2014.10590

. Violência Social e Belo Monte: o dito e o não dito nas condicionantes. In: INSTITUTO SOCIOAMBIENTAL (ISA). Belo Monte: não há condições para a Licença de Operação. Brasília: ISA, p. 140-147, 2015.

Direitos das crianças, controle social e práticas empresariais: mecanismos de enfrentamento às violações de direitos humanos no contexto da Usina Hidrelétrica de Belo Monte. Homa Publica: Revista Internacional de Direitos Humanos e Empresas, 1 (1), p. 199-220, nov. 2016.

OLIVEIRA, Assis da Costa; CONCEIÇÃO, Ronicleici Santos da; HORIZONTE, Jaquelini Santos do. Impactos de grandes obras na dinâmica urbana de crianças e adolescentes: a implantação da Usina de Belo Monte. Revista Ponto e Vírgula, n. 16, p. 185-205, 2014.

ORGANIZAÇÃO DAS NAÇÕES UNIDAS (ONU). Declaração sobre o Direito ao Desenvolvimento. 1986. Disponível em: http://www.dhnet.org.br/direitos/ sip/onu/ spovos/lex170a.htm

Convenção sobre os Direitos da Criança. Brasília: Casa Civil, 1990. Disponível em: http://www.planalto.gov.br/ccivil_03/decreto/1990-1994/ D99710.htm

Declaração e Programa de Ação da Conferência de Direitos Humanos. 1993. Disponível em: www.dhnet.org.br. 
Observación general № 16 (2013) sobre las obligaciones del Estado en relación con el impacto del sector empresarial en los derechos del niño. Nova Iorque: Comité de los Derechos del Niño, 2013. GE.13-42824.

PARKMAN, Allen M. The Application of Human Capital Theory to Article 27. In: ANDREWS, Arlene Bowers; KAUFMAN, Natalie Hevener (eds.). Implementing the U. N. Convention on the Rights of the Child: a standard of living adequatade for development. Westport, Connecticut; London: Praeger, p. 149-155, 1999.

PASIN, Jorge Antônio Bozoti; BORGES, Luiz Ferreira Xavier. A nova definição da parceria público-privada e sua aplicabilidade na gestão de infra-estrutura pública. Revista do BNDES, 10 (20), p. 173-196, 2003.

RIBEIRO, Gustavo Lins. Quanto maior melhor? Projetos de Grande Escala: uma forma de produção vinculada à expansão de sistemas socioeconômicos. In: PACHECO DE OLIVEIRA, João; COHN, Clarice (orgs.). Belo Monte e a questão indígena. Brasília: ABA, 2014.

RICHTER, Daniela; VIEIRA, Gustavo Oliveira; TERRA, Rosane Mariano R. B. A proteção internacional da infância e da juventude: perspectivas, contextos e desafios. In: PES, João Hélio Ferreira (coord.). Direitos humanos: crianças e adolescentes. Curitiba: Juruá, p. 43-68, 2010.

RODRIGUES, Marta M. Assumpção. Políticas públicas. São Paulo: Publifolha, 2011.

ROSSATO, Luciano Alves; LÉPORE, Paulo Eduardo; SANCHES, Rogério. Estatuto da Criança e do Adolescente comentado: Lei 8.069/1990: artigo por artigo. São Paulo: Editora Revista dos Tribunais, 2013.

SANTILLI, Juliana. Socioambientalismo e novos direitos: proteção jurídica à diversidade biológica e cultural. São Paulo: Peirópolis, 2005.

SCABIN, Flávia. Challenges for the protection of the rights of communities impacted by infrastructure projects in Brazil: A preliminary analysis. São Paulo: FGV, 2015. Disponível em: https://direitosp.fgv.br/sites/direitosp.fgv.br/ files/arquivos/working_paper_challenges_for_the_protection_of_the_rights_of_ communities_impacted_by_infrastructure_projects_in_brazil_1.pdf

SIGAUD, Lygia. A política "social" do setor elétrico. In: Sociedade e Estado, IV (1), p. 55-71, 1989. 
SILVEIRA, Mayra; VERONESE, Josiane Rose Petry. Normas constitucionais de proteção à criança e ao adolescente: uma questão de eficácia ou de desrespeito? In: VERONESE, Josiane Rose Petry; ROSSATO, Luciano Alves; LÉPORE, Paulo Eduardo (coords.). Estatuto da Criança e do Adolescente: 25 anos de desafios e conquistas. São Paulo: Saraiva, p. 115-132, 2015.

SOARES, Mairã. Participação e Garantia dos Direitos Humanos de Crianças e Adolescentes. In: PINHO, Vilma Aparecida; OLIVEIRA, Assis da Costa (orgs.). Direitos Infanto-Juvenis e Violência Sexual em Contexto de Grandes Obras: perspectivas e desafios. Belém: GTR, p. 149-153, 2014.

SOUZA, Regina Magalhães de. Protagonismo juvenil: o discurso da juventude sem voz. Revista Brasileira Adolescência e Conflitualidade, 1 (1), p. 1-28, 2009. Disponível em: http://www.observatoriodoensinomedio.ufpr.br/wp-content/ uploads/2014/02/Prota gonismo-juvenil-o-discurso-da-juventude-sem-voz.pdf

VÁZQUEZ, Daniel; DELAPLACE, Dometille. Políticas públicas na perspectiva de direitos humanos: um campo em construção. Revista Internacional de Direitos Humanos, 8 (14), 34-65, jun. 2011. Disponível em: http://www.surjournal.org

VEIGA, Laura da. Monitoramento. In: GIOVANNI, Geraldo Di; NOGUEIRA, Marco Aurélio (orgs). Dicionário de políticas públicas. 2 ed. São Paulo: Editora da Unesp; Fundap, p. 579-583, 2015.

VERDUM, Ricardo. Obras de infra-estrutura no contexto da integração SulAmericana. In: VERDUM, Ricardo (org.). Integração, usinas hidrelétricas e impactos socioambientais. Brasília: INESC, p. 13-40, 2007.

VERONESE, Josiane Rose Petry. O Estatuto da Criança e do Adolescente: um novo paradigma. In: VERONESE, Josiane Rose Petry; ROSSATO, Luciano Alves; LÉPORE, Paulo Eduardo (coords.). Estatuto da Criança e do Adolescente: 25 anos de desafios e conquistas. São Paulo: Saraiva, p. 21-40, 2015.

VOMMARO, Pablo. La disputa por lo público en América Latina. Las juventudes en las protestas y en la construcción de lo común. Revista Nueva Sociedad, 251, p. 55-69, jun. 2014. Disponible en: http://nuso.org/autor/ pablo-vommaro/

ZHOURI, Andrea. Belo Monte: crise do sistema ambiental e da democracia. ZHOURI, Andrea (org.). Desenvolvimento, reconhecimento de direitos e conflitos territoriais. Brasília: ABA, p 45-65, 2013. 
Recebido em: 20-7-2016

Aprovado em: 20-12-16

\section{Assis da Costa Oliveira}

Professor de Direitos Humanos da Universidade Federal do Pará. Doutorando pelo Programa de Pós-Graduação em Direito da Universidade de Brasília. Secretário de articulação do Institituto de Pesquisa, Direitos e Movimentos Sociais (IPDMS). Advogado. E-mail: assisdco@gmail.com

Universidade Federal do Pará. Av. Augusto Corrêa, nº01. CEP 66087-640 Belem, PA - Brasil.

\section{André Filipe Pereira Reid dos Santos}

Doutor em Ciências Humanas pelo Programa de Pós-graduação em Sociologia e Antropologia da Universidade Federal do Rio de Janeiro (UFRJ); professor/ pesquisador do Programa de Pós-graduação Stricto Sensu em Direitos e Garantias Fundamentais da Faculdade de Direito de Vitória (FDV). E-mail: afprsantos@gmail.com

Faculdade de Direito de Vitória. Programa de Pós-Graduação Stricto Sensu. Rua Juiz Alexandre Martins de Castro Filho, 215. Santa Lúcia. Vitória - ES CEP 29056-295 
